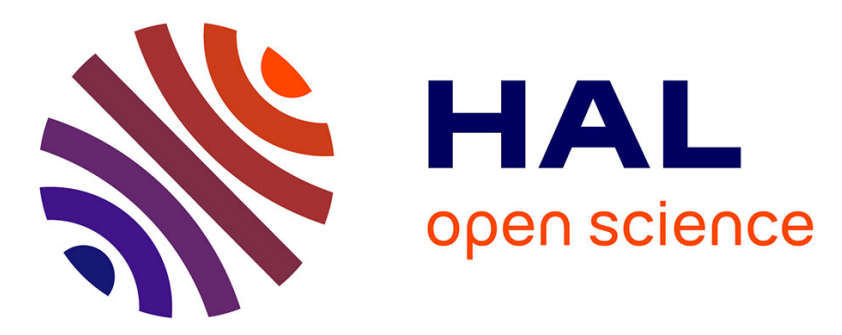

\title{
Contrasting NPQ dynamics and xanthophyll cycling in a motile and a non-motile intertidal benthic diatom
}

\author{
Lander Blommaert, Marie J J Huysman, Wim Vyverman, Johann Lavaud, \\ Koen Sabbe
}

\section{- To cite this version:}

Lander Blommaert, Marie J J Huysman, Wim Vyverman, Johann Lavaud, Koen Sabbe. Contrasting NPQ dynamics and xanthophyll cycling in a motile and a non-motile intertidal benthic diatom. Limnology and Oceanography, 2017, 62 (4), pp.1466-1479. 10.1002/lno.10511 . hal-02326554

\section{HAL Id: hal-02326554 \\ https://hal.science/hal-02326554}

Submitted on 22 Oct 2019

HAL is a multi-disciplinary open access archive for the deposit and dissemination of scientific research documents, whether they are published or not. The documents may come from teaching and research institutions in France or abroad, or from public or private research centers.
L'archive ouverte pluridisciplinaire HAL, est destinée au dépôt et à la diffusion de documents scientifiques de niveau recherche, publiés ou non, émanant des établissements d'enseignement et de recherche français ou étrangers, des laboratoires publics ou privés. 
5 Koen Sabbe ${ }^{1^{*}}$ Belgium quenching

Contrasting NPQ dynamics and xanthophyll cycling in a motile and a nonmotile intertidal benthic diatom

\section{Lander Blommaert ${ }^{1,4}$, Marie J. J. Huysman ${ }^{1,2,3}$, Wim Vyverman ${ }^{1}$, Johann Lavaud ${ }^{4,5}$ \&}

1 Ghent University, Lab. Protistology \& Aquatic Ecology, B-9000 Ghent, Belgium

2 VIB, Department of Plant Systems Biology, B-9052 Ghent, Belgium

3 Ghent University, Department of Plant Biotechnology and Bioinformatics, B-9052 Ghent,

4 CNRS/Université de La Rochelle, UMR7266 LIENSs, Institut du Littoral et de l'Environnement, 17000 La Rochelle, France

5 Current address : CNRS/Université Laval, UMI3376 Takuvik Joint International Laboratory, Département de Biologie, Pavillon Alexandre Vachon, Université Laval, 1045 avenue de la Médecine, Québec, Qc, G1V 0A6, Canada

* Corresponding author:

Ghent University, Lab. Protistology \& Aquatic Ecology, Krijgslaan 281-S8 B-9000 Ghent, Belgium, Phone: +32-(0)9-264-85-11, E-mail: koen.sabbe@ugent.be

Running head : Photoprotection in intertidal diatoms

Keywords: photoprotection, xanthophyll cycle, microphytobenthos, diatom, non-photochemical 


\section{Abstract}

24 Diatoms living in intertidal sediments have to be able to rapidly adjust photosynthesis in response

25 to often pronounced changes in light intensity during tidal cycles and changes in weather

26 conditions. Strategies to deal with oversaturating light conditions, however, differ between

27 growth forms. Motile epipelic diatoms can migrate to more optimal light conditions. In contrast,

28 non-motile epipsammic diatoms appear to mainly rely on higher Non-Photochemical Quenching

29 (NPQ) of chlorophyll $a$ fluorescence to dissipate excess light energy, and this has been related to

30 a larger pool of xanthophyll cycle (XC) pigments.

31 We studied the effect of $1 \mathrm{~h}$ high PAR (Photosynthetically Available Radiation) (2000 $\mu \mathrm{mol}$

32 photons $\mathrm{m}^{-2} \mathrm{~s}^{-1}$ ) on the kinetics of the xanthophyll cycle and NPQ in both a motile diatom

33 (Seminavis robusta) and a non-motile diatom (Opephora guenter-grassii) in an experimental set-

34 up which did not allow for vertical migration. O. guenter-grassii could rapidly switch NPQ on

35 and off by relying on fast XC kinetics. This species also demonstrated high de novo synthesis of

36 xanthophylls within a relatively short period of time (1 h), including significant amounts of

37 zeaxanthin, a feature not observed before in other diatoms. In contrast, S. robusta showed slower

38 NPQ and associated XC kinetics, partly relying on NPQ conferred by de novo synthetized

39 diatoxanthin molecules and synthesis of Light-Harvesting Complex X (LHCX) isoforms. Part of

40 this observed NPQ increase, however, is sustained quenching (NPQs). Our data illustrate the high

41 and diverse adaptive capacity of microalgal growth forms to maximize photosynthesis in

42 dynamic light environments. 


\section{Introduction}

48 Diatoms are dominant primary producers in areas characterized by pronounced fluctuations in

49 light conditions (Armbrust 2009; Lavaud and Goss 2014). Rapid changes in light climate in well

50 mixed waters or on intertidal flats challenge planktonic and benthic diatoms, respectively, to

51 adjust light harvesting to what can be safely used for photosynthesis. As periods of high light

52 conditions can result in oxidative damage to, in particular, the photosystem II (PSII) core,

53 diatoms possess various mechanisms to deal with high light stress: (1) avoid excess light energy

54 absorption by decreasing cell pigment content (MacIntyre et al. 2002); (2) dissipate excess

55 excitation energy as heat in a process called Non-Photochemical Quenching of chlorophyll $a$ (Chl

56 a) fluorescence (NPQ) (Lavaud and Goss 2014; Goss and Lepetit 2015), and/or by engaging

57 alternative electron cycling pathways (Wagner et al. 2016); (3) scavenge reactive oxygen species

58 (ROS) (Janknegt et al. 2008, 2009a; b; Waring et al. 2010); (4) repair damaged PSII cores,

59 mainly by replacing the D1 protein of the PSII reaction centre (Wu et al. 2011; Lavaud et al.

60 2016); (5) behavioural down regulation through vertical cell movement (microcycling and bulk

61 migration) (Kromkamp et al. 1998; Serôdio 2004). Of the above mechanisms, especially NPQ is

62 able to track fast light fluctuations experienced in the natural habitat (Brunet and Lavaud 2010;

63 Lavaud and Goss 2014).

64

65 In land plants, three NPQ components have been distinguished, based on the relaxation kinetics

66 after high light exposure: the rapidly relaxing component $\mathrm{qE}$ (seconds to minutes), the slower

67 state transitions qT (tens of minutes), and the so-called 'photoinhibitory' quenching qI, which

68 relaxes in the range of hours (Horton and Hague 1988). In diatoms, however, only two of these

69 have been observed (Owens 1986). Energy dependent quenching (qE) is the main component and 
70 is controlled by (1) the build-up of a proton gradient $(\Delta \mathrm{pH})$ across the thylakoid membrane, (2)

71 the (reversible) de-epoxidation of diadinoxanthin (Ddx) to diatoxanthin (Dtx) in the xanthophyll

72 cycle (XC) and (3) the presence of Light-Harvesting Complex X (LHCX) proteins, homologs of

73 the Light-Harvesting Complex Stress-Related (LHCSR) proteins found in green algae (Lavaud

74 and Goss 2014; Goss and Lepetit 2015). The origin of the second component (qI), however, is

75 less clear. Besides PSII photoinactivation and damage, Dtx and some LHCX isoforms might be

76 involved in this sustained quenching mechanism (Zhu and Green 2010; Lavaud and Lepetit

77 2013). It is increasingly referred to as NPQs (for sustained NPQ) or 'dark NPQ' as it persists

78 even under prolonged dark acclimation, particularly in intertidal benthic diatoms (Perkins et al.

79 2011; Lavaud and Goss 2014).

80

81 A molecular mechanism of $\mathrm{qE}$ in diatoms has been recently proposed (Lavaud and Goss 2014;

82 Goss and Lepetit 2015). qE is hypothesized to be based on two quenching sites within the LHC

83 antenna of PSII: 1) Q2 which is localized in a part of the LHC that remains attached to the PSII

84 and which directly depends on the synthesis and activation of Dtx, and 2) Q1 which is localized

85 in a part of the LHC that detaches from PSII upon Dtx activation at Q2 and which forms an

86 energy sink that amplifies Q2 quenching. It is believed that the persistence of Dtx, even in the

87 dark, is responsible for keeping both quenching sites active and especially Q1, i.e. as long as Dtx

88 is present at Q2 site, FCP (Fucoxanthin Chlorophyll a/c binding Protein) oligomers cannot

89 reconnect to PSII which generates part of the sustained qI/NPQs (Lavaud and Goss 2014).

90 Marked differences in NPQ capacity and kinetics were discovered between planktonic diatom

91 species and even between ecotypes isolated from habitats experiencing different degrees of

92 average irradiances and/or light fluctuations. These differences have been attributed either to

93 variation in XC kinetics and/or the amount of LHCX proteins (Lavaud et al. 2007; Dimier et al. 
95 The emerging picture from these reports is that a higher/faster Dtx synthesis supports a faster NPQ induction and a higher NPQ capacity in species/ecotypes adapted to habitats characterized

97 by strong light fluctuations and/or average higher irradiance (Lavaud and Goss 2014). One of the specificities is the de novo Dtx synthesis, which in case of prolonged stress light conditions helps to amplify photoprotection via enhanced NPQ and/or ROS scavenging (Lepetit et al. 2010). Species thriving in fluctuating light conditions, for example, exhibit high de novo synthesis of

Dtx molecules which correlates well with NPQ development during strong light conditions.

102 Species experiencing a more stable light climate in their natural habitat also synthetize Dtx molecules de novo when shifted to high light conditions but these are probably not involved in NPQ but may rather have an antioxidant function (Lavaud and Lepetit 2013). In addition to a high NPQ capacity and fast Dtx production during oversaturating light conditions, fast relaxation of NPQ in low light conditions is key to track changes in irradiance (Lavaud et al. 2007). As Dtx molecules have to be epoxidized back to Ddx to switch the antenna system from an energy dissipating to a light harvesting mode, diatoms with a high Dtx epoxidation rate dissipate NPQ faster compared to diatoms with a lower epoxidation rate (Goss et al. 2006; Goss and Jakob 2010). A difference in NPQ capacity can also be attributed to differences in LHCX protein content. The low amount of LHCX1 protein, for instance, explains limited NPQ capacity in a high latitude Phaeodactylum tricornutum ecotype isolated from a supralitoral rockpool (P.t.4) which experiences lower average light intensity, and less drastically fluctuating light conditions, 114 compared to other ecotypes (Bailleul et al. 2010). Whereas the $L H C X 1$ gene is already maximally expressed in low light conditions, several other $L H C X$ family members of both centric and 116 pennate diatoms are highly and rapidly upregulated when exposed to high light (Nymark et al. 2009; Park et al. 2010; Zhu and Green 2010; Lepetit et al. 2013, in press) and other stressful 
118 environmental conditions that impair photosynthetic capacity (Taddei et al. 2016). These proteins

119 might either confer higher NPQ capacity by binding newly synthetized Dtx molecules and/or be

120 involved in NPQs after prolonged high light exposure (Zhu and Green 2010; Lepetit et al. 2013,

121 in press).

122

123 While our knowledge of NPQ regulation is mostly based on studies of planktonic diatoms, whose

124 light climate is mostly governed by water column turbulence, far less attention has been paid to

125 NPQ regulation in benthic diatoms thriving in, and on, the sediments of intertidal flats (Jesus et

126 al. 2009; Perkins et al. 2010; Cartaxana et al. 2011, 2016a; b; Serôdio et al. 2012; Lavaud and

127 Goss 2014; Ezequiel et al. 2015; Pniewski et al. 2015; Laviale et al. 2015). Like terrestrial plants,

128 these diatoms can experience fast light fluctuations, not buffered by a water column, during low

129 tide. The tidal rhythm, furthermore, can change the light climate drastically as no or very little

130 light reaches the sediments in turbid estuaries when submerged (Underwood and Kromkamp

131 1999).

132

133 NPQ capacity of intertidal benthic diatoms is mainly defined by their ability or inability to avoid

134 excess light energy (Jesus et al. 2009; Cartaxana et al. 2011; Barnett et al. 2015). Diatoms

135 belonging to the raphid clade possess a raphe system that allows movement by secreting

136 extracellular polymer substances (EPS) through the raphe slit. Raphid diatoms can thus migrate

137 vertically into the sediment matrix to a more optimal light climate (Consalvey et al. 2004). In

138 addition, microcycling of motile diatoms within the top layers of the sediments was proposed

139 with algae migrating down to avoid photoinhibition being replaced by others (Kromkamp et al.

140 1998; Serôdio 2004). Such sequential turnover at the species level was indeed observed in 
141 laboratory mesocosms (Paterson 1986) and during an in situ emersion period (Underwood et al.

142 2005).

143

144 In contrast, diatoms living attached or in close association with single sand grains (epipsammic 145 diatoms) are immotile or only capable of limited movement and therefore need to rely on

146 physiological photoprotection (Cartaxana et al. 2011). This can explain a higher deepoxidation of

147 the Ddx-Dtx cycle pigments in epipsammic communities (Jesus et al. 2009). Barnett et al. (2015)

148 experimentally demonstrated higher NPQ values, coupled with higher Dtx content, in

149 epipsammic diatoms. A more comprehensive comparison between the regulation and kinetics of 150 the NPQ mechanism of both motile and non-motile diatoms, however, has so far not been made.

151 In this study we demonstrate fast irradiance tuning of NPQ, coupled with fast XC kinetics in the 152 immotile epipsammic diatom species Opephora guenter-grassii. We show that this species, in

153 addition to Dtx, also accumulates considerable amounts of the de-epoxidized xanthophyll 154 zeaxanthin $(\mathrm{Zx})$ during a short period $(1 \mathrm{~h})$ of high light exposure, a feature so far only observed 155 in planktonic diatoms after prolonged (up to $6 \mathrm{~h}$ ) periods of oversaturating light conditions (Lohr 156 and Wilhelm 1999). As the high de novo synthesis of de-epoxidized xanthophylls in this species 157 is not paralleled by an equal increase in NPQ, these xanthophylls are not expected to be directly 158 involved in the NPQ mechanism. In contrast, an epipelic species, Seminavis robusta, shows a less 159 dynamic NPQ, despite concerted de novo synthesis of both Dtx molecules and LHCX proteins.

160 Our findings add to the physiological underpinning of the differential response of motile and non161 motile diatom species (Juneau et al. 2015; Barnett et al. 2015) and of benthic diatom communities 162 in sediment (Pniewski et al. 2015; Laviale et al. 2015; Cartaxana et al. 2016b) to their 163 environment. 


\section{Materials}

\section{Culture conditions}

167 Strains were obtained from the diatom culture collection (BCCM/DCG) of the Belgian Coordinated 168 Collection of Micro-organisms (http://bccm.belspo.be), accession numbers Seminavis robusta 169 (DCG 0105) and Opephora guenter-grassii (DCG 0448), and grown in semi-continuous batch 170 culture in 1.81 glass Fernbach flasks (Schott) in a day/night rhythm of 16/8 hour with a 171 Photosynthetically Available Radiation (PAR) of $20 \mu \mathrm{mol}$ photons $\mathrm{m}^{-2} \mathrm{~s}^{-1}$. Cells were cultured in 172 Provasoli's enriched f/2 seawater medium using Tropic Marin artificial sea salt $\left(34.5 \mathrm{~g} \mathrm{l}^{-1}\right)$ enriched 173 with $\mathrm{NaHCO}_{3}\left(80 \mathrm{mg} 1^{-1}\right.$ final concentration). Cultures were acclimated to these culturing 174 conditions for at least 2 weeks. Chlorophyll $a(\mathrm{Chl} a)$ was measured daily according to Jeffrey \& 175 Humphrey (1975) to monitor growth.

\section{High light exposure}

178 Cultures in exponential growth were concentrated to $10 \mathrm{mg} \mathrm{Chl} a \mathrm{l}^{-1}$ by centrifugation 179 (Eppendorf $5810 \mathrm{R}$ ) at $4000 \mathrm{RCF}$ for $5 \mathrm{~min}$ in $50 \mathrm{ml}$ falcons. The cultures were again acclimated 180 to their growth conditions for $2 \mathrm{~h}$ before exposure to high light. Immediately before the experiment started $\mathrm{NaHCO}_{3}(4 \mathrm{mM}$, final concentration) was added from a $2 \mathrm{M}$ stock to prevent

182 carbon limitation during the experiment. Four $65 \mathrm{~W}$ white light energy-saving lamps (Lexman) 183 were used to provide high light (HL) conditions $\left(2000 \mu \mathrm{mol}\right.$ photons $\left.\mathrm{m}^{-2} \mathrm{~s}^{-1}\right)$ for one hour. Cells 184 were then allowed to recover for one hour in low light (LL, $20 \mu \mathrm{mol}$ photons $\mathrm{m}^{-2} \mathrm{~s}^{-1}$ ), provided by 185 one $20 \mathrm{~W}$ Lexman energy saving lamp. All light conditions were measured as PAR with a

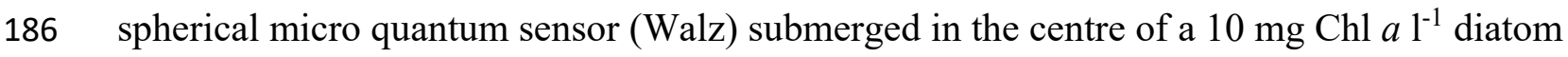
187 suspension, thus corresponding to the concentrations used during the experiments. Cells were 
continuously stirred in a glass test tube to obtain a homogenous cell suspension. This glass test tube was cooled in a custom-made glass cooler by a water bath at $20^{\circ} \mathrm{C}$.

\section{LHCX protein detection}

Sampling was conducted as described by Lepetit et al. (2013). Samples were taken immediately before light exposure (T0), after one hour HL and after one subsequent hour of LL recovery.

Protein extraction, SDS-PAGE, Western-blot and ECL immunodetection were carried out as published by Laviale et al. (2015). Both an FCP6 antibody (dilution 1/10000), Anti-FCP6 (LHCX1) from Cyclotella cryptica (Westermann and Rhiel 2005), and an anti-LHCSR3 (dilution 1/20000) from Chlamydomonas reinhardtii (Bonente et al. 2011) were tested. Anti-PsbB (CP47, Agrisera) was used as a loading control. Anti-LHCX6 from T. pseudonana (Zhu and Green 2010) was not usable for the two investigated species. Phaeodactylum tricornutum CCAP 1055/1 (P.t.) samples exposed to HL for 3 hours were analysed at the same time as a control.

\section{Pigment analyses}

Diatom suspensions were rapidly filtered onto Isopore $1.2 \mu \mathrm{m}$ RTTP filters (Merck Millipore), immediately frozen in liquid nitrogen and stored at $-80^{\circ} \mathrm{C}$. Samples were freeze-dried before adding $-20^{\circ} \mathrm{C}$ cold $1.4 \mathrm{ml}$ extraction buffer $(90 \%$ methanol/ $0.2 \mathrm{M}$ ammonium acetate $(90 / 10$ vol/vol) and 10\% ethyl acetate). Pigment extraction was enhanced by adding glass beads (diameter $0.25-0.5 \mathrm{~mm}$, Roth) and vortexing for $30 \mathrm{~s}$. The extracts were sonicated for $30 \mathrm{~s}$ on ice at $40 \%$ amplitude with $2 \mathrm{~s}$ pulse, $1 \mathrm{~s}$ rest and filtered over a $0.2 \mu \mathrm{m}$ filter. One hundred $\mu 1$ were immediately injected into the HPLC system (Agilent). Samples were analysed according to Van Heukelem and Thomas (2001). As buffered extraction medium was used, no additional TBAA 
211 buffer was injected. All pigment concentrations (chlorophyll $c(\mathrm{Chl} c)$, fucoxanthin (Fx),

212 diadinoxanthin (Ddx), diatoxanthin (Dtx), violaxanthin (Vx), antheraxanthin (Ax), zeaxanthin

213 (Zx), chlorophyll $a(\mathrm{Chl} a)$ and $\beta$-carotene $(\beta$-car)) were calculated by comparison with pigment

214 standards. All standards were obtained from DHI, with exception of Chl $a$ which was obtained

215 from Sigma-Aldrich.

216

217 Pulse Amplitude Modulated (PAM) Fluorometry

218 Chlorophyll fluorescence was measured using a Diving PAM fluorometer (Walz). Saturating

219 flashes $\left(0.4 \mathrm{~s}, 3600 \mu \mathrm{mol}\right.$ photons $\left.\mathrm{m}^{-2} \mathrm{~s}^{-1}\right)$ were provided by the internal halogen lamp to measure

220 photosynthetic parameters (see Barnett et al. 2015 for a complete overview of parameters). The

221 duration of $0.4 \mathrm{~s}$ for saturating pulses was tested as the best setting for measurement of the

222 maximum photosynthetic efficiency of PSII $\left(\mathrm{F}_{\mathrm{v}} / \mathrm{Fm}_{\mathrm{m}}\right)$ and effective quantum efficiency of PSII

223 photochemistry $\left(\Delta \mathrm{F} / \mathrm{F}_{\mathrm{m}}{ }^{\prime}\right)$. When applied longer, the maximal fluorescence yield $\left(\mathrm{F}_{\mathrm{m}}\right)$ is under-

224 estimated which artificially lowers $\mathrm{F}_{\mathrm{v}} / \mathrm{F}_{\mathrm{m}}$ and $\Delta \mathrm{F} / \mathrm{F}_{\mathrm{m}}$ '. This is most probably due to the high

225 energy delivered by the halogen lamp of the Diving-PAM fluorometer (different from the LEDs

226 used for most other PAM fluorometers). We have applied these settings before (see Barnett et al.

227 2015) and it provided reliable results. To avoid interference from the HL setup, the lights were

228 switched off immediately before firing a saturating pulse (see Lepetit et al. 2013). The

229 photosynthetic efficiency of PSII $\left(\Delta \mathrm{F} / \mathrm{F}_{\mathrm{m}}{ }^{\prime}\right)$ was calculated as $\left(\mathrm{F}_{\mathrm{m}}{ }^{\prime}-\mathrm{F}^{\prime}\right) / \mathrm{F}_{\mathrm{m}}{ }^{\prime}$ and expressed as a

230 percentage, taking the maximal photosynthetic efficiency $\left(\mathrm{F}_{\mathrm{v}} / \mathrm{F}_{\mathrm{m}}\right)$, measured immediately before

231 HL onset as $100 \%$. Non-Photochemical Quenching (NPQ) was calculated as $\left(\mathrm{F}_{\mathrm{m}}-\mathrm{F}_{\mathrm{m}}{ }^{\prime}\right) / \mathrm{F}_{\mathrm{m}}$ '.

\section{Rate estimation and statistics}


234 The $\Delta \mathrm{F} / \mathrm{F}_{\mathrm{m}}$ ' recovery rate constant $(\mathrm{k})$ was calculated by fitting an exponential decay function:

$235 \Delta \mathrm{F} / \mathrm{Fm}_{\mathrm{m}}{ }^{\prime}(\mathrm{t})=\Delta \mathrm{F} / \mathrm{Fm}^{\prime}{ }^{\prime}$ ec $+\left[\Delta \mathrm{F} / \mathrm{F}_{\mathrm{m}}{ }^{\prime}(0)-\Delta \mathrm{F} / \mathrm{F}_{\mathrm{m}}{ }^{\prime}\right.$ rec $] \mathrm{e}^{-\mathrm{kt}}$

236 where $\mathrm{t}$ represents time (in min) during recovery and $\Delta \mathrm{F} / \mathrm{Fm}{ }^{\prime}(0)$ and $\Delta \mathrm{F} / \mathrm{Fm}{ }^{\prime}$ rec represents $\Delta \mathrm{F} / \mathrm{Fm}_{\mathrm{m}}{ }^{\prime}$

237 (expressed in percentage from the $\Delta \mathrm{F} / \mathrm{F}_{\mathrm{m}}$ ' before $\mathrm{HL}$ onset) at the start of the recovery period and

238 after 30 min of recovery in LL respectively (Serôdio et al. 2012). Ddx de-epoxidation, Dtx and

239 Zx epoxidation and the XC de novo synthesis rates were calculated as in Lavaud et al. (2004)

240 using exponential decay functions for epoxidation and de-epoxidation rate constants (k). The Ddx

241 epoxidation, for instance, was fitted as the decrease of Ddx with the exponential decay function:

$242 \operatorname{Ddx}(\mathrm{t})=\operatorname{Ddx}$ minimal $+(\operatorname{Ddx}$ initial $-\mathrm{Ddx}$ minimal $) \mathrm{e}^{-\mathrm{kt}}$

243 where $t$ represents time (in min), and $\mathrm{Ddx}$ initial and Ddxminimal represent the highest and lowest

244 observed concentrations, respectively. Linear functions were fitted for xanthophyll de novo

245 synthesis rates. Statistical analyses were conducted using the statistical software package SAS

246 9.4. Species parameters (3 replicates per species) were compared using the general linear model

247 PROC GLM. In case of unequal variances, a Welch's t-test was performed. 


\section{$248 \quad$ Results}

\section{General characteristics}

250 The epipelic diatom Seminavis robusta and epipsammic diatom Opephora guenter-grassii were

251 grown under low light (LL) conditions; resulting in a XC pigment pool (Ddx + Dtx) of $4.94 \pm$ $2520.45 \mathrm{~mol}(100 \mathrm{~mol} \mathrm{Chl} a)^{-1}$ for S. robusta and $9.88 \pm 0.59 \mathrm{~mol}(100 \mathrm{~mol} \mathrm{Chl} a)^{-1}$ for O. guenter-

253 grassii. The maximal PSII quantum yield $\Delta \mathrm{F} / \mathrm{F}_{\mathrm{m}}$, measured immediately before HL exposure and 254 without dark adaptation, was $0.685 \pm 0.031$ for $S$. robusta and $0.665 \pm 0.017$ for $O$. guenter255 grassii and did not differ significantly $(p=0.099)$ between the two species. This indicates that the 256 cells were in an unstressed condition prior to HL exposure, which is also supported by the 257 absence or negligible concentrations of diatoxanthin (Dtx).

\section{PSII quantum yield and NPQ}

260 Both O. guenter-grassii and S. robusta were exposed to HL for one hour, after which they were

261 allowed to recover in LL conditions. The quantum yield of PSII $\left(\Delta \mathrm{F} / \mathrm{F}_{\mathrm{m}}{ }^{\prime}\right)$ of both species dropped 262 during HL (Fig. 1a), but was significantly higher for O. guenter-grassii at the end of the HL period in comparison with $S$. robusta $(p=0.049$, Welch-test). During the subsequent low light 264 conditions $\Delta \mathrm{F} / \mathrm{F}_{\mathrm{m}}$ ' of $O$. guenter-grassii recovered about $90 \%$ of its value before $\mathrm{HL}$ exposure whereas $S$. robusta recovered less than $75 \%$. The $\Delta \mathrm{F} / \mathrm{Fm}$ ' recovery rate constant was more than

266 double the rate constant for the epipsammic species $\left(0.096 \mathrm{~min}^{-1} \pm 0.009\right.$ compared to $0.040 \mathrm{~min}^{-}$

$267{ }^{1} \pm 0.004$ for S. robusta). At each time point during HL, NPQ was higher in O. guenter-grassii, 268 compared to $S$. robusta (Fig. 1b). During the start of the LL period, O. guenter-grassii showed 269 very rapid NPQ relaxation, with about half of its NPQ relaxing within 2.5 minutes. Both fast 270 NPQ relaxation and recovery of $\Delta \mathrm{F} / \mathrm{F}_{\mathrm{m}}$ ' slowed down when $O$. guenter-grassii was placed in 271 darkness instead of LL (Fig. 2a\&b). NPQ dissipation in S. robusta occurred more gradually and 
272 was incomplete after one hour of LL, with a remaining NPQ of $0.504 \pm 0.07$ compared to $0.188 \pm$ 2730.002 for O. guenter-grassii.

275 Xanthophyll cycle characteristics

276 The higher Ddx-Dtx pool of $O$. guenter-grassii $(p=0.000)$ resulted in higher Dtx concentrations 277 after 5 minutes of HL $(p=0.0447)$ (Fig. 3a\&b, Table 1). The de-epoxidation state (DES, 278 calculated as Dtx/(Ddx + Dtx $))$, however, was not significantly different between the species 279 during the HL period (Fig. 4). From 15 minutes onwards the total Ddx + Dtx pool increased (due 280 to de novo synthesis of xanthophylls) with similar rates in both species (Fig. 3a\&b, Table 1).

281 During one hour of HL treatment each species synthetized an additional 2 mol Ddx + Dtx (100 mol Chl $a)^{-1}$. At the end of the HL period O. guenter-grassii contained significantly $(p=0.040)$ 283 more Dtx $\left(5.69 \pm 1.41 \mathrm{~mol}(100 \mathrm{~mol} \mathrm{Chl} a)^{-1}\right)$ than S. robusta $\left(3.15 \pm 0.42 \mathrm{~mol}(100 \mathrm{~mol} \mathrm{Chl} a)^{-1}\right)$ 284 (Table 1). Due to the lower amount of Dtx originating from de-epoxidation of Ddx in S. robusta 285 and similar de novo Dtx synthesis as O. guenter-grassii, the relative contribution of de novo 286 synthetized Dtx was about two-thirds of the accumulated Dtx in S. robusta, whereas the de novo 287 contribution was only one third in the case of O. guenter-grassii.

288 During the LL recovery period, Dtx was rapidly epoxidized by O. guenter-grassii. Its Dtx 289 epoxidation rate constant in LL was about 5 times higher than in $S$. robusta $(p=0.003)$ (see 290 Table 1), with most Dtx being epoxidized to Ddx within the first 5 min of LL recovery. 291 Epoxidation occurred more gradually in $S$. robusta (Fig. 3a\&b). Differences in epoxidation rate 292 resulted in significant differences in de-epoxidation state at $5(p=0.022)$ and $15 \min (p=0.019)$ 293 during the LL recovery period (Fig. 4). At the end of the recovery period however, nearly all Dtx 294 had disappeared in both species (Fig. 3a\&b, Table 1). The fast Dtx epoxidation by O. guenter- 
grassii in LL was not observed in darkness (Fig. 2c). In both species, an increase in the Ddx + 296 Dtx pool was recorded during LL treatment. O. guenter-grassii gained $2.26 \pm 0.21 \mathrm{~mol} \mathrm{Ddx}+$ 297 Dtx $(100 \mathrm{~mol} \mathrm{Chl} a)^{-1}$, whereas in S. robusta the increase was $1.84 \pm 1.10 \mathrm{~mol}$ Ddx + Dtx $(100$ 298 mol Chl $a)^{-1}$ (Table 1).

299 Besides the Dtx cycle pigments, pigments of the violaxanthin (Vx) cycle were detected in both 300 species during HL (Fig. 3c\&d, Table 1). O. guenter-grassii accumulated about 2 mol (100 mol $301 \mathrm{Chl} a)^{-1}$ Vx cycle pigments during the HL period (Table 1). At the end of the HL treatment, 1.34 $302 \pm 0.19 \mathrm{~mol}(100 \mathrm{~mol} \mathrm{Chl} a)^{-1}$ of the de-epoxidized pigment Zeaxanthin (Zx) was detected in $O$. 303 guenter-grassii. The intermediate between Zx and Vx, antheraxanthin (Ax), was also detected 304 during HL (Fig. 3c). In comparison, S. robusta accumulated significantly less $(p=0.001) \mathrm{Vx}$ 305 cycle pigments (Fig. 3d) and both Zx and Ax were only present in trace amounts. During the LL recovery period epoxidation of Zx started immediately in O. guenter-grassii, resulting in a short peak of $\mathrm{Ax}$ (at time point 2.5-5 min) and an increase in $\mathrm{Vx}$. The total $\mathrm{Vx}$ cycle pool $(\mathrm{Vx}+\mathrm{Ax}+$ 308 Zx) decreased markedly for both species during LL with a decrease of $1.62 \pm 0.48 \mathrm{~mol}(100 \mathrm{~mol}$ Chl $a)^{-1}$ for $O$. guenter-grassii and a smaller decrease of $0.07 \pm 0.02 \mathrm{~mol}(100 \mathrm{~mol} \mathrm{Chl} a)^{-1}$ for $S$. 310 robusta. Notably, in O. guenter-grassii, Vx cycle pigments decreased as fast during the LL 311 period as new Ddx cycle pigments were synthetized $\left(0.28 \mathrm{mmol}(\mathrm{mol} \mathrm{Chl} a)^{-1} \mathrm{~min}^{-1} \pm 0.08\right.$ and $0.36 \mathrm{mmol}(\mathrm{mol} \mathrm{Chl} a)^{-1} \mathrm{~min}^{-1} \pm 0.05$ respectively). During the course of the experiment no notable changes in $\mathrm{Fx}, \mathrm{Chl} c$ and $\beta$-car were observed (Data not shown).

\section{Correlation between Dtx accumulation and NPQ}

316 NPQ correlated well with Dtx mol (100 mol Chl $a)^{-1}$ for both species (Fig. 5). They showed 317 similar slopes (0.7-0.8) until about $3 \mathrm{Dtx}$ mol (100 mol Chl $a)^{-1}$, after which less NPQ was 318 developed per mol Dtx for O. guenter-grassii. The relationship remained true for S. robusta 
319 during the course of the experiment. Its Dtx content, nevertheless, did not exceed the threshold at

320 which the curve slope changed in $O$. guenter-grassii. The y-axis intercept differed from zero for

321 S. robusta, as was reported earlier (Barnett et al. 2015).

322

\section{LHCX presence during $\mathrm{HL}$}

324 For immunodetection of LHCX-isoforms in O. guenter-grassii (Fig. 6a) the best results were

325 obtained using the anti-FCP6 antibody, as less a-specific binding occurred in comparison with the

326 LHCSR3 antibody. Only one LHCX isoform could be detected with a molecular weight close to

327 that of Phaeodactylum tricornutum LHCX3 (22.24 KDa). This isoform was apparent in LL

328 acclimated cells and increased in abundance during the one hour of $\mathrm{HL}$ and the subsequent hour

329 of recovery in LL.

330 In S. robusta (Fig. 6b) only the anti-LHCSR3 antibody revealed LHCX isoforms. One isoform, 331 with a molecular weight equal to $P$. tricornutum LHCX3 $(22.24 \mathrm{KDa})$ and another more faint 332 band with an equal size to $P$. tricornutum LHCX2 $(24.73 \mathrm{KDa})$ were present in LL acclimated 333 cells. The former increased in abundance during HL and subsequent recovery in LL. After one 334 hour of HL, moreover, two additional LHCX isoforms could be detected. An LHCX isoform of 335 about $23 \mathrm{KDa}$ was clearly present after one hour of $\mathrm{HL}$ and after the additional recovery period. 336 The second one, about the size of LHCX1 in P. tricornutum (21.95 KDa), became visible after 337 one hour of HL. 


\section{Discussion}

341 In this study we demonstrate marked differences in irradiance tuning of NPQ and associated XC

342 pigment and LHCX protein dynamics between a motile and a non-motile marine benthic diatom.

343 The non-motile species (O. guenter-grassii) exhibits a dynamic and strong high-energy

344 quenching (qE), coupled to fast XC kinetics and pronounced synthesis of de-epoxidized

345 xanthophylls, including zeaxanthin. In this species, strong physiological photoprotection may

346 compensate for its lack of motility as a way to avoid oversaturating light conditions. The motile

347 species (S. robusta) on the other hand exhibited an overall lower qE capacity, even though NPQ

348 increased during the light period, possibly due to de novo synthesis of both Dtx and LHCX

349 proteins.

350

351 Prior to the experiments, both species were acclimated to low light conditions, to avoid the 352 presence of Dtx and NPQ in cultures, as much as possible, which could bias the measurement of $353 \quad \mathrm{~F}_{\mathrm{m}}$. These growth conditions resulted in similar XC content as observed by Barnett et al. (2015) 354 under identical light conditions for the same benthic species used in this study, and also as 355 observed for a range of planktonic species grown in a PAR of $40 \mu \mathrm{mol}$ photons $\mathrm{m}^{-2} \mathrm{~s}^{-1}$ (Lavaud et 356 al. 2004). The non-motile epipsammic species $O$. guenter-grassii showed higher NPQ during 357 high light exposure, compared to the epipelic diatom S. robusta. As reported by Barnett et al. 358 (2015), higher NPQ values coincided with a higher overall Dtx content de-epoxidized from a 359 larger initial Ddx pool, rather than a higher de-epoxidation state (DES) or a higher involvement 360 of Dtx molecules in the NPQ mechanism (Lavaud and Lepetit 2013). Indeed, we did not observe 361 a difference in DES between O. guenter-grassii and S. robusta, nor a difference in the slopes of 362 the NPQ/Dtx plots. Note that Jesus et al. (2009), working on natural epipelic and epipsammic 
communities, did observe a difference in DES between both, but this may have been due to high

364 light avoidance by vertical migration and/or microcycling in the epipelic communities, which was 365 impeded in our study.

366 Accumulation of Dtx, independent from Ddx de-epoxidation, was observed for both species

367 during high light exposure as reported for planktonic diatoms (Lavaud et al. 2004; Lavaud and

368 Lepetit 2013) and natural epipelic communities (Laviale et al. 2015). The rate constant of this de

369 novo Dtx synthesis was similar for both species and in the range of planktonic diatoms exposed

370 to the same HL conditions (Lavaud et al. 2004), resulting in the same increase of the Ddx + Dtx

371 pool. The XC pool at the end of the HL period, nonetheless, was still relatively low for both

372 species, as up to $26 \mathrm{~mol} \mathrm{Ddx}+\operatorname{Dtx}(100 \mathrm{~mol} \mathrm{Chl} a)^{-1}$ were observed by Lohr and Wilhelm (1999)

373 in Cyclotella meneghiniana and even up to 30-40 Ddx $+\operatorname{Dtx}(100 \mathrm{~mol} \mathrm{Chl} a)^{-1}$ in Chaetoceros

374 socialis (Dimier et al. 2007). These large XC pools, however, required a prolonged exposure (i.e.,

375 several hours) to high irradiances, whereas in this study the HL period was relatively short (1 h).

376 In the diatoms Plagiogramma staurophorum and Brockmanniella brockmannii, nonetheless,

377 acclimation to a PAR of $75 \mu$ mol photons $\mathrm{m}^{-2} \mathrm{~s}^{-1}$ resulted in XC pools higher than $25 \mathrm{Ddx}+\mathrm{Dtx}$

378 (100 mol Chl $a)^{-1}$ (Barnett et al. 2015).

379 The involvement of de novo synthetized Dtx differed between both species. Whereas the NPQ-

380 Dtx relationship remained true for S. robusta, de novo synthetized Dtx in O. guenter-grassii did

381 not contribute equally to the NPQ mechanism, as shown by a decline in the NPQ-Dtx

382 relationship. Part of this additionally synthetized Dtx is possibly present in the lipid matrix of the 383 thylakoid membrane (Schumann et al. 2007) to prevent lipid peroxidation (Lepetit et al. 2010). It

384 should be noted, however, that the total Dtx values observed for S. robusta during our

385 experiments remained rather low compared to values recorded for other species using a similar

386 setup (Lavaud et al. 2004; Lepetit et al. 2013; Lavaud and Lepetit 2013) and might be due to a 
small Ddx pool before HL onset (Lavaud et al. 2004). A stable NPQ/Dtx slope during de novo 388 synthesis of Dtx, as observed in S. robusta, nonetheless, may indicate synthesis of new Dtx389 binding proteins such as LHCXs (Lepetit et al. 2013).

390 As fast epoxidation of Dtx is crucial to switch the light harvesting system from an energy 391 dissipation state to a light harvesting state, we monitored NPQ relaxation and Dtx epoxidation 392 during low light following high light exposure. O. guenter-grassii displayed very rapid Dtx 393 epoxidation coupled with an equally fast NPQ relaxation, but not during dark recovery, as 394 previously reported (Goss et al. 2006b). This is also demonstrated by the fast recovery of PSII 395 quantum yield in low light, which is severely restricted in darkness as the epoxidation reaction is 396 possibly slowed down by NADPH depletion (Goss et al. 2006b). The fast reversal of NPQ and 397 nearly complete recovery of PSII quantum yield, moreover, indicate that the observed high NPQ 398 values comprise mostly qE while qI/NPQs is virtually absent.

399 A fast switch from energy dissipation to light harvesting after high light exposure was not 400 observed in the epipelic diatom S. robusta, where Dtx epoxidation and coupled NPQ relaxation 401 occurred more gradually. Together with an incomplete and slower recovery of PSII quantum 402 yield our data demonstrate a higher susceptibility to photoinhibition during prolonged high light 403 as has been shown for species isolated from habitats lacking strong light fluctuations (Goss et al. 404 2006b; Su et al. 2012; Lavaud and Lepetit 2013). The observed NPQ values, increasing during 405 the high light treatment, therefore comprise not only qE but also a significant fraction of qI due to 406 PSII photoinactivation and damage (since Dtx is almost fully converted back to Ddx).

407 Even though both $S$. robusta and O. guenter-grassii accumulated similar amounts of newly 408 synthetized Dtx within one hour of high light, the latter synthetized the same amount of Vx cycle 409 and Dtx cycle pigments, including Zx. The presence of a parallel Vx-Ax-Zx cycle has been 410 demonstrated in several algae possessing the Ddx-Dtx cycle, including the diatom species 
412 accumulation in these species, however, required prolonged (up to 6 hours) high light exposure

413 (Lohr and Wilhelm 1999, 2001) and has never been reported in studies on P. tricornutum using

414 similar PAR and exposure time (i.e. within one hour, $2000 \mu \mathrm{mol}$ photons $\mathrm{m}^{-2} \mathrm{~s}^{-1}$ ) as used in this

415 study (Lavaud et al. 2004; Domingues et al. 2012; Lepetit et al. 2013; Lavaud and Lepetit 2013).

416 Epoxidation of Zx in low light was as fast as Dtx epoxidation, while the second epoxidation step

417 occurred more slowly, resulting in a transient peak in the intermediate Ax. This transient peak in

418 Ax has been reported before for the green alga Chlorella (Goss et al. 2006a). The Vx cycle pool

419 of $O$. guenter-grassii declined during the one hour recovery period and to a lesser degree also in

420 S. robusta, whereas a similar Vx cycle pool decline in P. tricornutum was not observed within

421 one hour of low light recovery (Lohr \& Wilhelm, 1999). The high amount of Vx cycle pigments

422 synthetized by $O$. guenter-grassii in high light may have been converted to Ddx during the

423 recovery period, as the decline in Vx cycle pigments was paralleled by an equal increase in Ddx

$424+$ Dtx. A pathway from Vx to Ddx through the intermediate neoxanthin has been proposed by

425 Dambek et al. (2012). In S. robusta, however, more Ddx + Dtx accumulated during the LL period

426 than was lost from the Vx cycle pool. This might be due to additional synthesis of Ddx cycle

427 pigments during low light, even though additional de novo synthesis in low light conditions is

428 considered to be low (Lohr \& Wilhelm, 1999). According to Lohr and Wilhelm (1999, 2001), the

429 primary role of $\mathrm{Vx}$ cycle pigments in diatoms is not photoprotection as they mainly serve as

430 intermediates in Ddx and fucoxanthin production. Increasing the light intensity, nonetheless,

431 changes the allocation of newly synthesized xanthophylls to the Vx-Ax-Zx pool in P. tricornutum

432 (Lohr and Wilhelm 1999). Moreover, Vx cycle pigments are mostly detected in algae displaying

433 high de novo xanthophyll synthesis combined with high de-epoxidase activity. This fits with our

434 observations of $O$. guenter-grassii, de novo synthetizing substantially more xanthophylls 
435 (considering both Ddx and Zx cycle pigments) and de-epoxidising more Ddx to Dtx during HL

436 than S. robusta. We do not expect Zx to be directly involved in the NPQ mechanism of $O$.

437 guenter-grassii as the NPQ/Dtx relationship decreased during de novo synthesis of both

438 xanthophylls. In higher plants, Zx can dissolve in the thylakoid membrane lipids instead of being

439 protein bound (Jahns et al. 2009), scavenging reactive oxygen species with a higher capacity than

440 other xanthophylls found in higher plants (Havaux et al. 2007), or possibly regulating membrane

441 fluidity (Havaux and Gruszecki 1993).

442 As LHCX proteins play a central role in the NPQ mechanism of diatoms (Bailleul et al. 2010;

443 Zhu and Green 2010; Lepetit et al. 2013), we compared LHCX synthesis for the first time

444 between an epipsammic and an epipelic diatom. We could detect only one LHCX isoform $(\sim 22$

$445 \mathrm{kDa}$ ) in the epipsammic model O. guenter-grassii using the FCP6 antibody. It did not strongly

446 react to a shift to high light and was more abundant in subsequent low light. The epipelic diatom

447 S. robusta, however, revealed two out of four isoforms which strongly reacted to HL: one

448 isoform with MW $\sim 23 \mathrm{kDa}$ and a second one with MW $\sim 19 \mathrm{kDa}$. Interestingly, in epipelic

449 communities, a $23 \mathrm{kDa}$ isoform was shown to positively reacts to high light, high temperature

450 and motility inhibition (Laviale et al. 2015). The two isoforms already present in low light might

451 provide benthic diatoms with a basic NPQ to rapidly cope with sudden changes in light climate,

452 as has been demonstrated for LHCX1 of P. tricornutum (Bailleul et al., 2010). However, the $S$.

453 robusta genome does not contain a close homolog to the P. tricornutum LHCX1 gene at the

454 sequence level (L. Blommaert et al., data not shown). LHCXs which are strongly upregulated

455 during high light have been suspected to either bind de novo synthetized Dtx, conferring higher

456 NPQ and/or participate in a sustained component of NPQ (NPQs) after prolonged high light

457 exposure (Zhu and Green 2010; Lepetit et al. 2013, in press). As S. robusta accumulates novel

458 Dtx during HL while its NPQ increases, the two observed light-responsive LHCX isoforms may 
459 be responsible for Dtx binding, as suggested by Zhu and Green (2010), and Lepetit et al. (2013, 460 in press). However, other FCP proteins may be responsible as for instance the LHCR6 and

461 LHCR8 (Light-Harvesting Complex Red lineage) genes are strongly upregulated in $P$.

462 tricornutum, upon a shift to high light (Nymark et al. 2009).

463

464 Ecological implications

465 A fast and strong irradiance-tuning of NPQ is to be expected in immotile epipsammic diatoms as 466 they live attached to sand grains (Ribeiro et al. 2013) and are unable to move away from 467 oversaturating light conditions. Furthermore, sandy sediments are characterized by strong light 468 scattering in the uppermost layers, thereby increasing the average incident irradiance to which these 469 diatoms are exposed (Kuhl et al. 1994; Cartaxana et al. 2016b). Even though our epipsammic 470 species was acclimated to low PAR $\left(20 \mu \mathrm{mol}\right.$ photons $\left.\mathrm{m}^{-2} \mathrm{~s}^{-1}\right)$ it was able to cope with a sudden 471 change to a light intensity similar to full sunlight. Similar transitions from low to full sunlight (and

472 vice versa) can be common in sandy sediments during low tide (Hamels et al. 1998). Given the 473 prolonged harsh light conditions in these sediments, epipsammic diatoms probably demonstrate a 474 high de novo synthesis of photoprotective xanthophylls in situ, including Zx. This can also explain 475 the previously observed discrepancy between high Zx content and absence of colonial 476 cyanobacteria (containing Zx) in sandy sediments, as reported in Hamels et al. (1998). Taken 477 together, our results suggest that epipsammic diatoms use a combination of distinct photoprotective 478 strategies described by Lavaud and Lepetit (2013) to cope with the light climate of sandy intertidal 479 sediments: (1) a strong and fast reversible qE to track light fluctuations, combined with (2) high de 480 novo synthesis of de-epoxidized xanthophylls, probably unbound to the LHC antenna system, 481 which may fulfil an anti-oxidant function during prolonged light conditions. Even though our study 
was performed on only one epipsammic representative, a strong $\mathrm{qE}$ and a relatively higher $\mathrm{XC}$ pool

483 (compared to epipelic species) seem to be general for epipsammic species (Barnett et al. 2015).

484 The epipelic model S. robusta displayed a lower NPQ consisting partly of photoinhibition (qI).

485 This is expected as epipelic diatoms use vertical migration and/or microcycling as their primary

486 photoprotection mechanism when motility is allowed (Kromkamp et al. 1998; Serôdio 2004;

487 Perkins et al. 2010; Cartaxana et al. 2011; Serôdio et al. 2012; Laviale et al. 2015). Furthermore,

488 vertical migration is fast enough to reduce the amount of absorbed photons and can operate

489 simultaneously with NPQ induction (Laviale et al. 2016). Both synthesis of new Dtx pigments and

490 LHCX proteins, nonetheless, have been shown in epipelic communities under high light conditions

491 (Laviale et al. 2015), which is in line with our findings. Furthermore, our data suggests the

492 involvement of light-regulated LHCX proteins during harsh light conditions, allowing epipelic

493 species to acclimate to prolonged higher light conditions (Ezequiel et al. 2015; Barnett et al. 2015).

494 Hence, although adapted to a habitat with more cohesive sediments, characterized by a strongly

495 attenuated photic zone (Cartaxana et al. 2016b), epipelic diatoms still possess the ability to increase

496 their low basal photoprotective ability. The fact that epipelic species have been shown to emerge

497 at the sediment surface at different times during tidal emersion suggests that they have different

498 species-specific light niches (Paterson 1986; Underwood et al. 2005). As a result, their capacity for

499 physiological photoprotection is also expected to differ between species. Future studies, therefore,

500 should focus on the interspecific differences in the balance between behavioural and physiological

501 photoprotection. 


\section{References}

Armbrust, E. V. 2009. The life of diatoms in the world's oceans. Nature 459: 185-92. doi:10.1038/nature08057

Bailleul, B., A. Rogato, A. de Martino, S. Coesel, P. Cardol, C. Bowler, A. Falciatore, and G. Finazzi. 2010. An atypical member of the light-harvesting complex stress-related protein family modulates diatom responses to light. Proc. Natl. Acad. Sci. 107: 18214-18219. doi:10.1073/pnas. 1007703107

Barnett, A., V. Méléder, L. Blommaert, and others. 2015. Growth form defines physiological photoprotective capacity in intertidal benthic diatoms. ISME J. 9: 32-45. doi:10.1038/ismej.2014.105

Bonente, G., M. Ballottari, T. B. Truong, T. Morosinotto, T. K. Ahn, G. R. Fleming, K. K. Niyogi, and R. Bassi. 2011. Analysis of LhcSR3, a protein essential for feedback deexcitation in the green alga Chlamydomonas reinhardtii. T. Shikanai [ed.]. PLoS Biol. 9: e1000577. doi:10.1371/journal.pbio.1000577

Brunet, C., and J. Lavaud. 2010. Can the xanthophyll cycle help extract the essence of the microalgal functional response to a variable light environment? J. Plankton Res. 32: 16091617. doi:10.1093/plankt/fbq104

Cartaxana, P., S. Cruz, C. Gameiro, and M. Kühl. 2016a. Regulation of intertidal microphytobenthos photosynthesis over a diel emersion period is strongly affected by diatom migration patterns. Front. Microbiol. 7: 872. doi:10.3389/fmicb.2016.00872

Cartaxana, P., L. Ribeiro, J. Goessling, S. Cruz, and M. Kühl. 2016b. Light and O2 microenvironments in two contrasting diatom-dominated coastal sediments. Mar. Ecol. Prog. Ser. 545: 35-47. doi:10.3354/meps 11630

Cartaxana, P., M. Ruivo, C. Hubas, I. Davidson, J. Serôdio, and B. Jesus. 2011. Physiological versus behavioral photoprotection in intertidal epipelic and epipsammic benthic diatom communities. J. Exp. Mar. Bio. Ecol. 405: 120-127. doi:10.1016/j.jembe.2011.05.027

Consalvey, M., D. M. Paterson, and G. J. C. Underwood. 2004. The ups and downs of life in a benthic biofilm: Migration of benthic diatoms. Diatom Res. 19: 181-202.

Dambek, M., U. Eilers, J. Breitenbach, S. Steiger, C. Büchel, and G. Sandmann. 2012. Biosynthesis of fucoxanthin and diadinoxanthin and function of initial pathway genes in Phaeodactylum tricornutum. J. Exp. Bot. 63: 5607-5612. doi:10.1093/jxb/ers211

Dimier, C., F. Corato, F. Tramontano, and C. Brunet. 2007. Photoprotection and xanthophyll cycle activity in three marine diatoms. J. Phycol. 43: 937-947. doi:10.1111/j.15298817.2007.00381.x

Domingues, N., A. R. Matos, J. Marques da Silva, and P. Cartaxana. 2012. Response of the diatom Phaeodactylum tricornutum to photooxidative stress resulting from high light exposure. PLoS One 7: e38162. doi:10.1371/journal.pone.0038162

Ezequiel, J., M. Laviale, S. Frankenbach, P. Cartaxana, and J. Serôdio. 2015. Photoacclimation 
state determines the photobehaviour of motile microalgae: The case of a benthic diatom. J.

Exp. Mar. Bio. Ecol. 468: 11-20. doi:10.1016/j.jembe.2015.03.004

Goss, R., and T. Jakob. 2010. Regulation and function of xanthophyll cycle-dependent photoprotection in algae. Photosynth. Res. 106: 103-122. doi:10.1007/s11120-010-9536-X

Goss, R., and B. Lepetit. 2015. Biodiversity of NPQ. J. Plant Physiol. 172: 13-32. doi:10.1016/j.jplph.2014.03.004

Goss, R., B. Lepetit, and C. Wilhelm. 2006a. Evidence for a rebinding of antheraxanthin to the light-harvesting complex during the epoxidation reaction of the violaxanthin cycle. J. Plant Physiol. 163: 585-590. doi:10.1016/j.jplph.2005.07.009

Goss, R., E. A. Pinto, C. Wilhelm, and M. Richter. 2006b. The importance of a highly active and $\Delta \mathrm{pH}-$-regulated diatoxanthin epoxidase for the regulation of the PS II antenna function in diadinoxanthin cycle containing algae. J. Plant Physiol. 163: 1008-1021. doi:10.1016/j.jplph.2005.09.008

Hamels, I., K. Sabbe, K. Muylaert, C. Lucas, P. Herman, and W. Vyverman. 1998. Organisation of Microbenthic Communities. Eur. J. Protistol. 34: 308-320.

Havaux, M., L. Dall'osto, and R. Bassi. 2007. Zeaxanthin has enhanced antioxidant capacity with respect to all other xanthophylls in Arabidopsis leaves and functions independent of binding to PSII antennae. Plant Physiol. 145: 1506-1520. doi:10.1104/pp.107.108480

Havaux, M., and W. I. Gruszecki. 1993. Heat and light induced chlorophull a fluorescence changes in potato leaves containign high or low levels of the carotenoid zeaxanthin: indications of a regulatory effect of zeaxanthin on thylakoid fluidity. Photochem. Photobiol. 58: 607-614. doi:10.1111/j.1751-1097.1993.tb04940.x

Van Heukelem, L., and C. S. Thomas. 2001. f phytoplankton pigments. J. Chromatogr. A 910: $31-49$.

Horton, P., and A. Hague. 1988. Studies on the induction of chlorophyll fluorescence in isolated barley protoplasts. IV. Resolution of non - photochemical quenching. Biochim. Biophys. Acta 932: 107-115.

Jahns, P., D. Latowski, and K. Strzalka. 2009. Mechanism and regulation of the violaxanthin cycle: the role of antenna proteins and membrane lipids. Biochim. Biophys. Acta 1787: $3-$ 14. doi:10.1016/j.bbabio.2008.09.013

Janknegt, P. J., C. M. De Graaff, W. H. Van De Poll, R. J. W. Visser, E. W. Helbling, and A. G. J. Buma. 2009a. Antioxidative responses of two marine microalgae during acclimation to static and fluctuating natural uv radiation. Photochem. Photobiol. 85: 1336-1345. doi:10.1111/j.1751-1097.2009.00603.x

Janknegt, P. J., C. M. De Graaff, W. H. Van De Poll, R. J. W. Visser, J. W. Rijstenbil, and A. G. J. Buma. 2009b. Short-term antioxidative responses of 15 microalgae exposed to excessive irradiance including ultraviolet radiation. Eur. J. Phycol. 44: 525-539. doi:10.1080/09670260902943273 
Janknegt, P. J., W. H. van de Poll, R. J. W. Visser, J. W. Rijstenbil, and A. G. J. Buma. 2008. Oxidative Stress Responses in the Marine Antarctic Diatom Chaetoceros Brevis (Bacillariophyceae) During Photoacclimation 1. J. Phycol. 44: 957-966. doi:10.1111/j.15298817.2008.00553.x

Jeffrey, S. W., and G. S. Humphrey. 1975. New spectrophotometric equations for determining chlorophylls a, b, c1 and c2 in higher plants, algae and natural phytoplankton. Biochem Physiol Pflanz. Bd 167: 191-194.

Jesus, B., V. Brotas, L. Ribeiro, C. R. Mendes, P. Cartaxana, and D. M. Paterson. 2009. Adaptations of microphytobenthos assemblages to sediment type and tidal position. Cont. Shelf Res. 29: 1624-1634. doi:10.1016/j.csr.2009.05.006

Juneau, P., A. Barnett, V. Méléder, C. Dupuy, and J. Lavaud. 2015. Combined effect of high light and high salinity on the regulation of photosynthesis in three diatom species belonging to the main growth forms of intertidal flat inhabiting microphytobenthos. J. Exp. Mar. Bio. Ecol. 463: 95-104. doi:10.1016/j.jembe.2014.11.003

Kromkamp, J. C., C. Barranguet, and J. Peene. 1998. Determination of microphytobenthos PSII quantum efficiency and photosynthetic activity by means of variable chlorophyll fluorescence. Mar. Ecol. Prog. Ser.

Kuhl, M., C. Lassen, and B. B. Jorgensen. 1994. Light penetration and light intensity in sandy marine sediments measured with irradiance and scalar irradiance fiber-optic microprobes. Mar. Ecol. Prog. Ser. 105: 139-148. doi:10.3354/meps 105139

Lavaud, J., and R. Goss. 2014. The peculiar features of the non-photochemical fluorescence quenching in diatoms and brown algae, p. 421-443. In Non-Photochemical Quenching and Energy Dissipation in Plants, Algae and Cyanobacteria. Springer.

Lavaud, J., and B. Lepetit. 2013. An explanation for the inter-species variability of the photoprotective non-photochemical chlorophyll fluorescence quenching in diatoms. Biochim. Biophys. Acta 1827: 294-302. doi:10.1016/j.bbabio.2012.11.012

Lavaud, J., B. Rousseau, and A.-L. Etienne. 2004. General Features of Photoprotection By Energy Dissipation in Planktonic Diatoms (Bacillariophyceae). J. Phycol. 40: 130-137. doi:10.1046/j.1529-8817.2004.03026.x

Lavaud, J., C. Six, and D. A. Campbell. 2016. Photosystem II repair in marine diatoms with contrasting photophysiologies. Photosynth. Res. 127: 189-199. doi:10.1007/s11120-0150172-3

Lavaud, J., R. F. Strzepek, and P. G. Kroth. 2007. Photoprotection capacity differs among diatoms : Possible consequences on the spatial distribution of diatoms related to fluctuations in the underwater light climate. Limnol. Oceanogr. 52: 1188-1194.

Laviale, M., A. Barnett, J. Ezequiel, B. Lepetit, S. Frankenbach, V. Méléder, J. Serôdio, and J. Lavaud. 2015. Response of intertidal benthic microalgal biofilms to a coupled lighttemperature stress: evidence for latitudinal adaptation along the Atlantic coast of Southern Europe. Environ. Microbiol. 17: 3662-3677. doi:10.1111/1462-2920.12728 
Laviale, M., S. Frankenbach, and J. Serôdio. 2016. The importance of being fast: comparative kinetics of vertical migration and non-photochemical quenching of benthic diatoms under light stress. Mar. Biol. 163: 10. doi:10.1007/s00227-015-2793-7

Lepetit, B., G. Gélin, M. Lepetit, and others. In press. The diatom Phaeodactylum tricornutum adjusts nonphotochemical fluorescence quenching capacity in response to dynamic light via fine-tuned Lhcx and xanthophyll cycle pigment synthesis. New Phytol. doi:10.1111/nph.14337

Lepetit, B., S. Sturm, A. Rogato, A. Gruber, M. Sachse, A. Falciatore, P. G. Kroth, and J. Lavaud. 2013. High light acclimation in the secondary plastids containing diatom Phaeodactylum tricornutum is triggered by the redox state of the plastoquinone pool. Plant Physiol. 161: 853-865. doi:10.1104/pp.112.207811

Lepetit, B., D. Volke, M. Gilbert, C. Wilhelm, and R. Goss. 2010. Evidence for the existence of one antenna-associated, lipid-dissolved and two protein-bound pools of diadinoxanthin cycle pigments in diatoms. Plant Physiol. 154: 1905-1920. doi:10.1104/pp.110.166454

Lohr, M., and C. Wilhelm. 1999. Algae displaying the diadinoxanthin cycle also possess the violaxanthin cycle. Proc. Natl. Acad. Sci. 96: 8784-8789.

Lohr, M., and C. Wilhelm. 2001. Xanthophyll synthesis in diatoms: quantification of putative intermediates and comparison of pigment conversion kinetics with rate constants derived from a model. Planta 212: 382-391. doi:10.1007/s004250000403

MacIntyre, H. L., T. M. Kana, T. Anning, and R. J. Geider. 2002. Photoacclimation of photosynthesis irradiance response curves and photosynthetic pigments in macroalgae and cyanobacteria. J. Phycol. 38: 17-38. doi:10.1046/j.1529-8817.2002.00094.x

Nymark, M., K. C. Valle, T. Brembu, K. Hancke, P. Winge, K. Andresen, G. Johnsen, and A. M. Bones. 2009. An integrated analysis of molecular acclimation to high light in the marine diatom Phaeodactylum tricornutum. PLoS One 4: e7743. doi:10.1371/journal.pone.0007743

Owens, T. G. 1986. Light-Harvesting Function in the Diatom Phaeodactylum tricornutum II. distribution of excitation energy between photosystems. 80: 739-746.

Park, S., G. Jung, Y. Hwang, and E. Jin. 2010. Dynamic response of the transcriptome of a psychrophilic diatom, Chaetoceros neogracile, to high irradiance. Planta 231: 349-60. doi:10.1007/s00425-009-1044-X

Paterson, D. M. 1986. The migratory behaviour of diatom assemblages in a laboratory tidal micro-ecosystem examined by low temperature scanning electron microscopy. Diatom Res. 1: 227-239. doi:10.1080/0269249X.1986.9704971

Perkins, R. G., J. C. Kromkamp, J. Serôdio, J. Lavaud, B. Jesus, J. L. Mouget, S. Lefebvre, and R. M. Forster. 2011. The application of variable chlorophyll fluorescence to microphytobenthic biofilms, p. 237-275. In Chlorophyll a Fluorescence in Aquatic Sciences: Methods and Applications. Springer Netherlands.

Perkins, R., J. Lavaud, J. Serôdio, and others. 2010. Vertical cell movement is a primary response 
of intertidal benthic biofilms to increasing light dose. Mar. Ecol. Prog. Ser. 416: 93-103. doi: $10.3354 /$ meps 08787

Petrou, K., M. A. Doblin, and P. J. Ralph. 2011. Heterogeneity in the photoprotective capacity of three Antarctic diatoms during short-term changes in salinity and temperature. Mar. Biol. 158: 1029-1041. doi:10.1007/s00227-011-1628-4

Pniewski, F. F., P. Biskup, I. Bubak, P. Richard, A. Latała, and G. Blanchard. 2015. Photoregulation in microphytobenthos from intertidal mudflats and non-tidal coastal shallows. Estuar. Coast. Shelf Sci. 152: 153-161. doi:10.1016/j.ecss.2014.11.022

Ribeiro, L., V. Brotas, Y. Rincé, and B. Jesus. 2013. Structure and diversity of intertidal benthic diatom assemblages in contrasting shores: a case study from the Tagus estuary. J. Phycol. 49: 258-270. doi:10.1111/jpy.12031

Schumann, A., R. Goss, T. Jakob, and C. Wilhelm. 2007. Investigation of the quenching efficiency of diatoxanthin in cells of Phaeodactylum tricornutum (Bacillariophyceae) with different pool sizes of xanthophyll cycle pigments. Phycologia 46: 113-117. doi:10.2216/06-30.1

Serôdio, J. 2004. Analysis of variable chlorophyll fluorescence in microphytobenthos assemblages: implications of the use of depth-integrated measurements. Aquat. Microb. Ecol. 36: 137-152. doi:10.3354/ame036137

Serôdio, J., J. Ezequiel, A. Barnett, J. Mouget, V. Méléder, M. Laviale, and J. Lavaud. 2012. Efficiency of photoprotection in microphytobenthos: role of vertical migration and the xanthophyll cycle against photoinhibition. Aquat. Microb. Ecol. 67: 161-175. doi:10.3354/ame01591

Su, W., T. Jakob, and C. Wilhelm. 2012. the Impact of Nonphotochemical Quenching of Fluorescence on the Photon Balance in Diatoms Under Dynamic Light Conditions. J. Phycol. 48: 336-346. doi:10.1111/j.1529-8817.2012.01128.x

Taddei, L., G. R. Stella, A. Rogato, and others. 2016. Multisignal control of expression of the LHCX protein family in the marine diatom Phaeodactylum tricornutum. J. Exp. Bot. 67: 3939-3951. doi:10.1093/jxb/erw198

Underwood, G. J. C., and J. Kromkamp. 1999. Primary production by phytoplankton and microphytobenthos in estuaries estuaries. Adv. Ecol. Res. 29: 93-153. doi:10.1016/S00652504(08)60192-0

Underwood, G. J. C., R. G. Perkins, M. C. Consalvey, A. R. M. Hanlon, K. Oxborough, N. R. Baker, and D. M. Paterson. 2005. Patterns in microphytobenthic primary productivity: Species-specific variation in migratory rhythms and photosynthesis in mixed-species biofilms. Limnol. Oceanogr. 50: 755-767. doi:10.4319/1o.2005.50.3.0755

Wagner, H., T. Jakob, J. Lavaud, and C. Wilhelm. 2016. Photosystem II cycle activity and alternative electron transport in the diatom Phaeodactylum tricornutum under dynamic light conditions and nitrogen limitation. Photosynth. Res. 128: 151-161. 
694 Waring, J., M. Klenell, U. Bechtold, G. J. C. Underwood, and N. R. Baker. 2010. Light-Induced Responses of Oxygen Photoreduction, Reactive Oxygen Species Production and Scavenging

697 Westermann, M., and E. Rhiel. 2005. Localisation of fucoxanthin chlorophyll a/c-binding 698 polypeptides of the centric diatom Cyclotella cryptica by immuno-electron microscopy. Protoplasma 225: 217-223. doi:10.1007/s00709-005-0083-9

700

701

702

703

704

705

706

707
Wu, H., A. M. Cockshutt, A. McCarthy, and D. a Campbell. 2011. Distinctive photosystem II photoinactivation and protein dynamics in marine diatoms. Plant Physiol. 156: 2184-95. doi:10.1104/pp.111.178772

Zhu, S.-H., and B. R. Green. 2010. Photoprotection in the diatom Thalassiosira pseudonana: role of LI818-like proteins in response to high light stress. Biochim. Biophys. Acta 1797: 144957. doi:10.1016/j.bbabio.2010.04.003 


\section{Acknowledgements}

709 The authors would like to thank the Research Foundation Flanders (FWO project G.0222.09N),

710 Ghent University (BOF-GOA 01G01911) and the Egide/Campus France-PHC Tournesol

711 (n128992UA) exchange program for their financial support. JL also thanks the CNRS and the

712 French consortium CPER Littoral for their financial support. M.J.J.H. acknowledges a

713 Postdoctoral Fellowship of the Research Foundation Flanders.

714 


\section{Figure legends}

\section{Fig. 1a\&b Photophysiological measurements}

717 O. guenter-grassii (filled circles) and S. robusta (open circles) were exposed to one hour of HL 718 (2000 $\mu \mathrm{M}$ photons $\left.\mathrm{m}^{-2} \mathrm{~s}^{-1}\right)$ and one subsequent hour of recovery in low light (LL, $20 \mu \mathrm{M}$ photons

$\left.719 \mathrm{~m}^{-2} \mathrm{~s}^{-1}\right)$. The quantum yield of PSII $\left(\Delta \mathrm{F} / \mathrm{Fm}^{\prime}\right)(\mathbf{a})$, expressed in percentage of the maximal

720 photosynthetic efficiency of PSII $\left(\mathrm{F}_{\mathrm{v}} / \mathrm{F}_{\mathrm{m}}\right)$ before HL exposure and (b) Non-photochemical

721 quenching (NPQ). Values represent averages of three independent measurements \pm standard

722 deviations.

723 Fig. 2 Dark recovery of $O$. guenter-grassii after HL exposure

724 O. guenter-grassii was exposed to one hour of HL $\left(2000 \mu \mathrm{M}\right.$ photons $\left.\mathrm{m}^{-2} \mathrm{~s}^{-1}\right)$ and one subsequent 725 hour of recovery in low light (LL, $20 \mu \mathrm{M}$ photons $\mathrm{m}^{-2} \mathrm{~s}^{-1}$ )(filled circles) or in dark recovery (open

726 circles) with LL onset at 105 min (indicated by an arrow). (a) Photosynthetic efficiency of PSII

$727 \Delta \mathrm{F} / \mathrm{F}_{\mathrm{m}}$ ' is expressed in percentage of the maximal photosynthetic efficiency of PSII $\left(\mathrm{F}_{\mathrm{v}} / \mathrm{F}_{\mathrm{m}}\right)$

728 measured before high light onset. (b) Non-photochemical quenching (NPQ) and (c) Dtx,

729 expressed in mol $(100 \mathrm{~mol} \mathrm{Chl} a)^{-1}$. Values represent averages of three independent

730 measurements \pm standard deviations for the low light recovery treatment. For the dark recovery

731 treatment, only one replicate is plotted.

733 Fig. 3a,b,c\&d Xanthophyll cycle kinetics

734 O. guenter-grassii and S. robusta were exposed to one hour of HL $\left(2000 \mu \mathrm{M}\right.$ photons $\left.\mathrm{m}^{-2} \mathrm{~s}^{-1}\right)$ and 735 one subsequent hour of recovery in low light (LL, $20 \mu \mathrm{M}$ photons $\left.\mathrm{m}^{-2} \mathrm{~s}^{-1}\right)$. (a) Diadinoxanthin 
cycle kinetics of O. guenter-grassii; (b) Diadinoxanthin cycle kinetics of S. robusta; (c)

737 Violaxanthin cycle kinetics of O. guenter-grassii; (d) Violaxanthin cycle kinetics of S. robusta.

738 Short dashed lines represent the epoxidized pigment (Ddx or Vx) whereas solid lines represent

739 the fully de-epoxidized pigment (Dtx of Zx). The grey line represents the intermediate Ax. Long

740 dashed lines represent the sum of all xanthophylls per cycle. Values represent averages of three

741 independent measurements \pm standard deviations.

\section{$742 \quad$ Fig. 4 De-epoxidation state of $O$. guenter-grassii and $S$. robusta}

743 O. guenter-grassii (filled circles) and S. robusta (open circles) were exposed to one hour of HL

$744\left(2000 \mu \mathrm{M}\right.$ photons $\left.\mathrm{m}^{-2} \mathrm{~s}^{-1}\right)$ and one subsequent hour of recovery in low light (LL, $20 \mu \mathrm{M}$ photons

$\left.745 \mathrm{~m}^{-2} \mathrm{~s}^{-1}\right)$. De-epoxidation state (DES) was calculated as 100[Dtx/(Ddx + Dtx)].

\section{Fig. 5a\&b Relationship between NPQ and Dtx}

747 NPQ is plotted in function of Dtx, sampled at the same timepoints for O. guenter-grassii (a, 748 circles) and $S$. robusta (b, triangles), exposed to one hour of HL $\left(2000 \mu \mathrm{M}\right.$ photons $\left.\mathrm{m}^{-2} \mathrm{~s}^{-1}\right)$ and 749 one subsesquent hour of recovery in low light ( $\mathrm{LL}, 20 \mu \mathrm{M}$ photons $\left.\mathrm{m}^{-2} \mathrm{~s}^{-1}\right)$. White symbols 750 represent data points sampled during HL, whereas black symbols represent data points sampled 751 during LL recovery. For $O$. guenter-grassii a distinction is made in the relationship below (solid 752 line, slope $p<0.001)$ and above 3 mol Dtx $(100 \mathrm{~mol} \mathrm{Chl} a)^{-1}$ (dashed line, slope $\left.p<0.001\right)$. The $753 \mathrm{NPQ} / \mathrm{Dtx}$ relationship for $S$. robusta is represented by a dotted line (slope $p<0.001$, intercept $p<$ 754 0.001).

\section{Fig. 6a\&b Western blot of LHCX proteins}

756 Western blot of (a) O. guenter-grassii using an FCP6 antibody and (b) S. robusta using anti-

757 LHCSR3 sampled before (T0) exposure to HL (2000 $\mu \mathrm{M}$ photons $\left.\mathrm{m}^{-2} \mathrm{~s}^{-1}\right)$, after one hour of HL 
758 (HL) and after one subsequent hour of recovery in LL $\left(20 \mu \mathrm{M}\right.$ photons $\left.\mathrm{m}^{-2} \mathrm{~s}^{-1}\right)(\mathrm{HL}+\mathrm{LL})$. An 759 antibody against the plastid encoded PsbB (CP47) protein was used as a loading control.

760 Phaeodactylum tricornutum (P.t.) samples which were exposed to HL for 3 hours were analysed 761 at the same time as a control. Phaeodactylum samples showed three LHCX bands using the 762 LHCSR3 antibody which were previously identified as LHCX1, LHCX2 and LHCX3 (Lepetit et 763 al., 2013). Identification of P.t. LHCX2\&3 was less clear using the FCP6 antibody in (a). 


\begin{tabular}{|c|c|c|}
\hline & S. robusta & O. guenter-grassii \\
\hline Ddx + Dtx content & 4.942 & 9.880 \\
\hline$\left[\mathrm{mol}(100 \mathrm{Chl} a)^{-1}\right]$ & \pm 0.479 & \pm 0.594 \\
\hline Dtx after $60 \mathrm{~min} H \mathrm{HL}$ & 3.146 & 5.685 \\
\hline$\left[\mathrm{mol}(100 \mathrm{Chl} a)^{-1}\right]$ & \pm 0.424 & \pm 1.413 \\
\hline Ddx deepoxidaton rate & 0.081 & 0.164 \\
\hline$\left[\mathrm{min}^{-1}\right]$ & \pm 0.017 & \pm 0.0521 \\
\hline De novo synthetized Dtx & 1.976 & 2.138 \\
\hline$\left[\mathrm{mol}(100 \mathrm{Chl} a)^{-1}\right]$ & \pm 0.422 & \pm 0.612 \\
\hline Dtx de novo synthesis rate & 0.341 & 0.444 \\
\hline$\left[\mathrm{mmol}(\mathrm{mol} \mathrm{Chl} a)^{-1} \mathrm{~min}^{-1}\right]$ & \pm 0.035 & \pm 0.065 \\
\hline De novo synthetized Vx cycle pigments & 0.131 & 2.043 \\
\hline$\left[\mathrm{mol}(100 \mathrm{Chl} a)^{-1}\right]$ & \pm 0.010 & \pm 0.216 \\
\hline De novo synthesis rate Vx cycle pigments & 0.0185 & 0.35 \\
\hline$\left[\mathrm{mmol}(\mathrm{mol} \mathrm{Chl} a)^{-1} \mathrm{~min}^{-1}\right]$ & \pm 0.009 & \pm 0.025 \\
\hline Dtx epoxidation rate in LL & 0.08 & 0.406 \\
\hline$\left[\min ^{-1}\right]$ & \pm 0.01 & \pm 0.144 \\
\hline $\begin{array}{c}\text { Zx epoxidation rate in LL } \\
{\left[\mathrm{min}^{-1}\right]}\end{array}$ & n.d. & $\begin{array}{l}\mathbf{0 . 3 1 1} \\
\pm 0.060\end{array}$ \\
\hline
\end{tabular}


769 Abbreviations: Chl $a$, Chlorophyll $a$; Ddx, diadinoxanthin; Dtx, diatoxanthin; Vx, violaxanthin; 770 Zx, zeaxanthin. All pigments are expressed as mol $(100 \mathrm{~mol} \text { chlorophyll } a)^{-1}$. Epoxidation and de771 epoxidation rates are calculated by fitting exponential decay functions. De novo synthesis rates 772 were fitted with linear functions. Values represent averages of three independent measurements \pm 773 standard deviations.

774 
$775 \quad$ Figures

776

777 Fig. 1a\&b

778

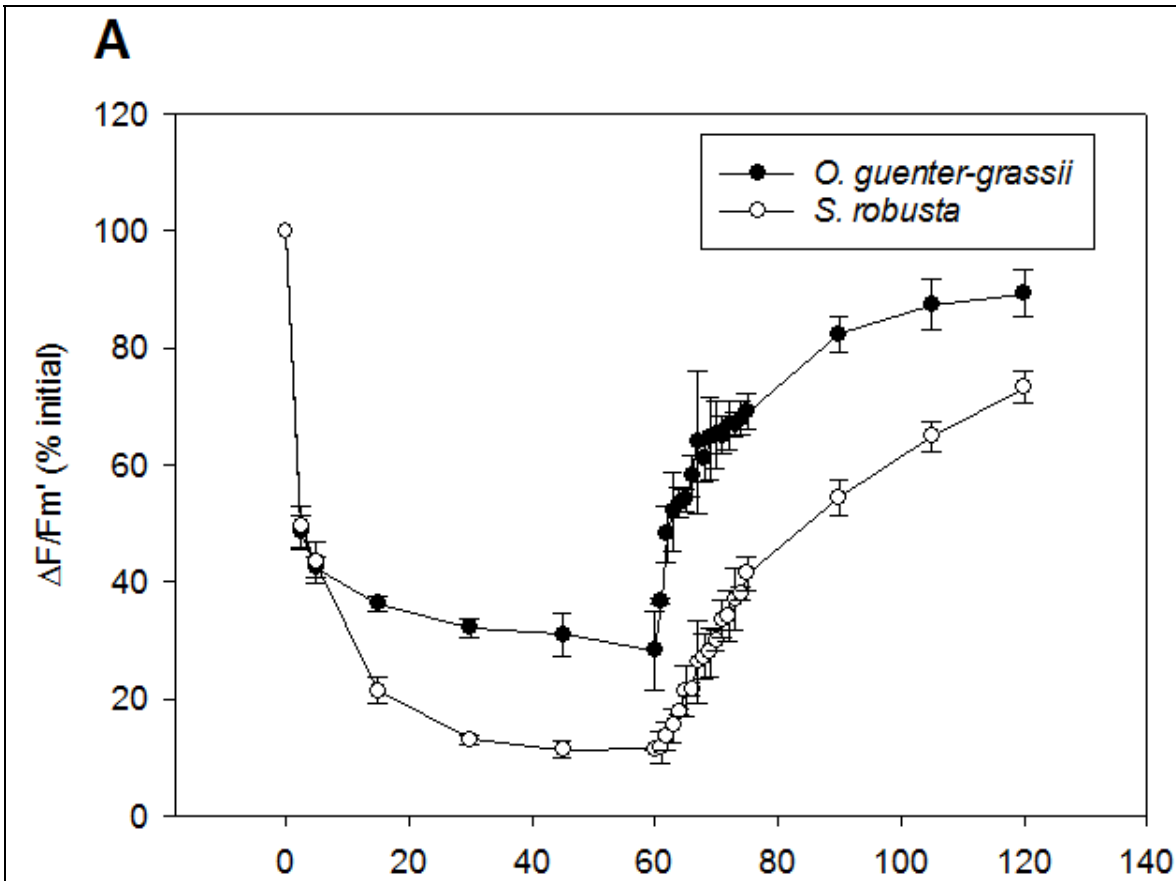

788

$\mathrm{HL} \quad$ Time [min]

LL

789

B

790

791

792

793

794

795

796

797

798

799

800

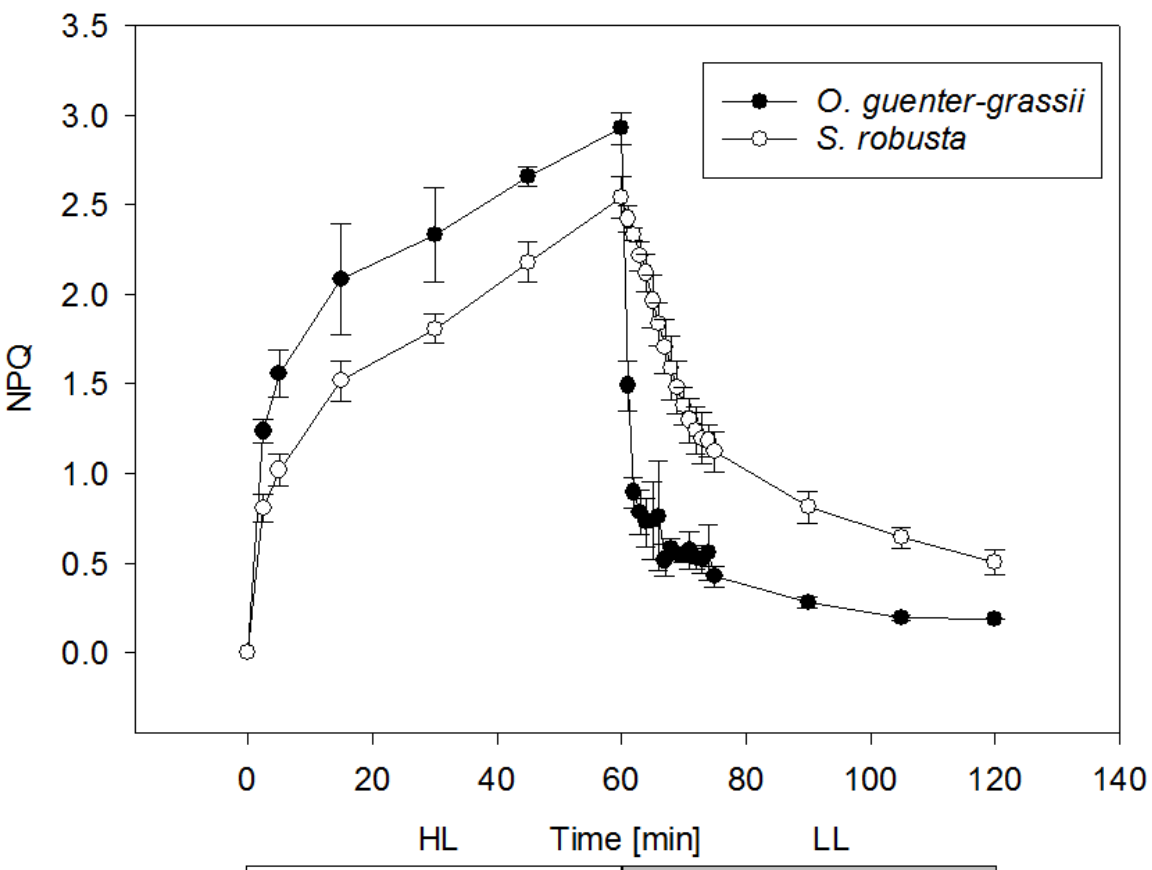

801 


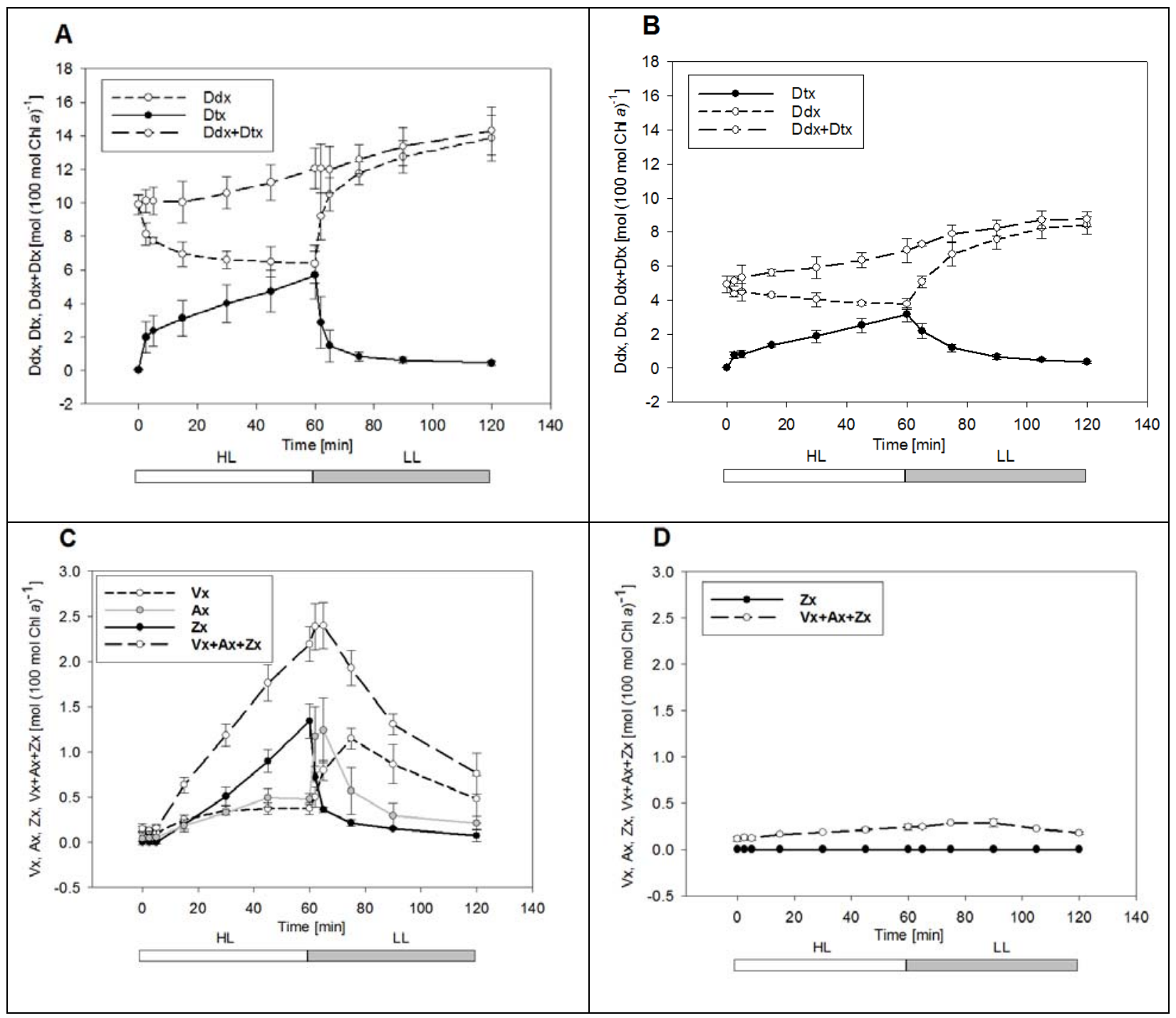

803

804

805 


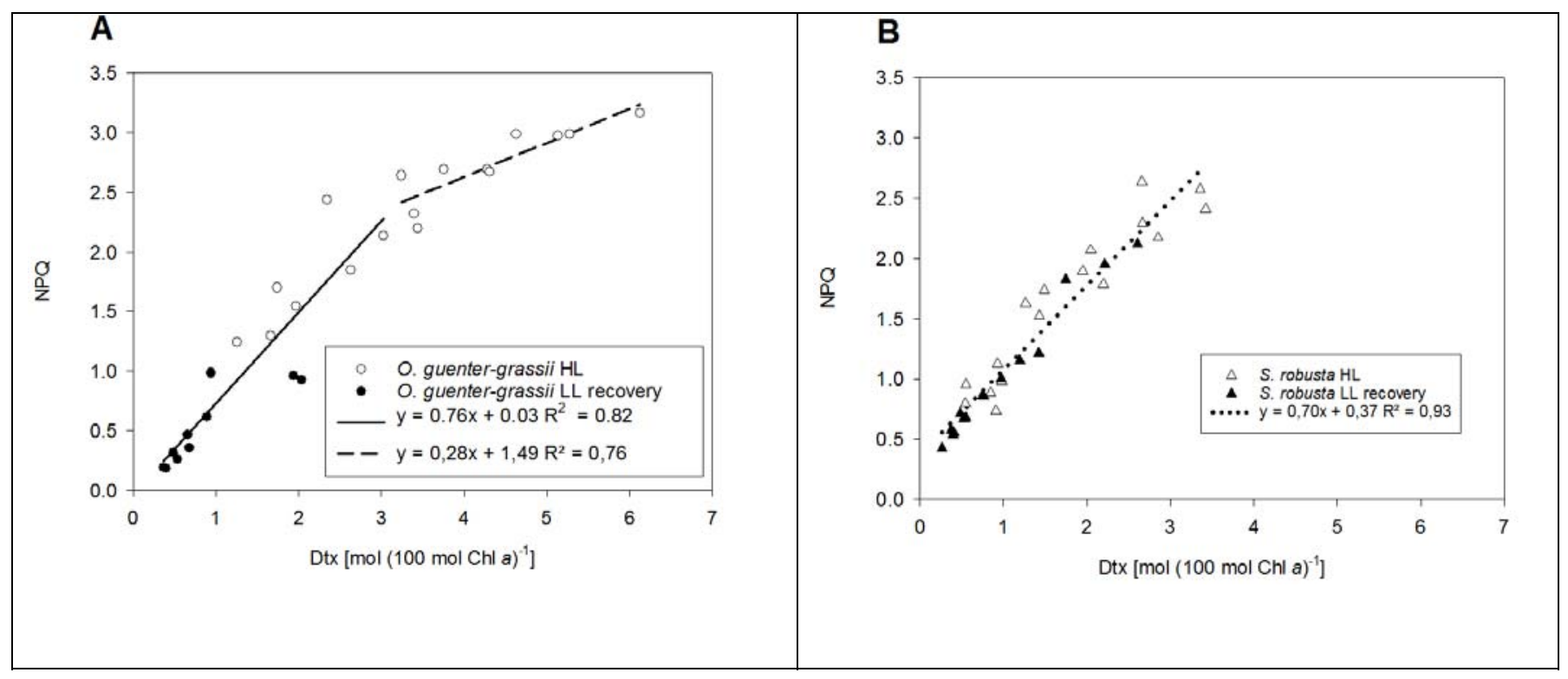




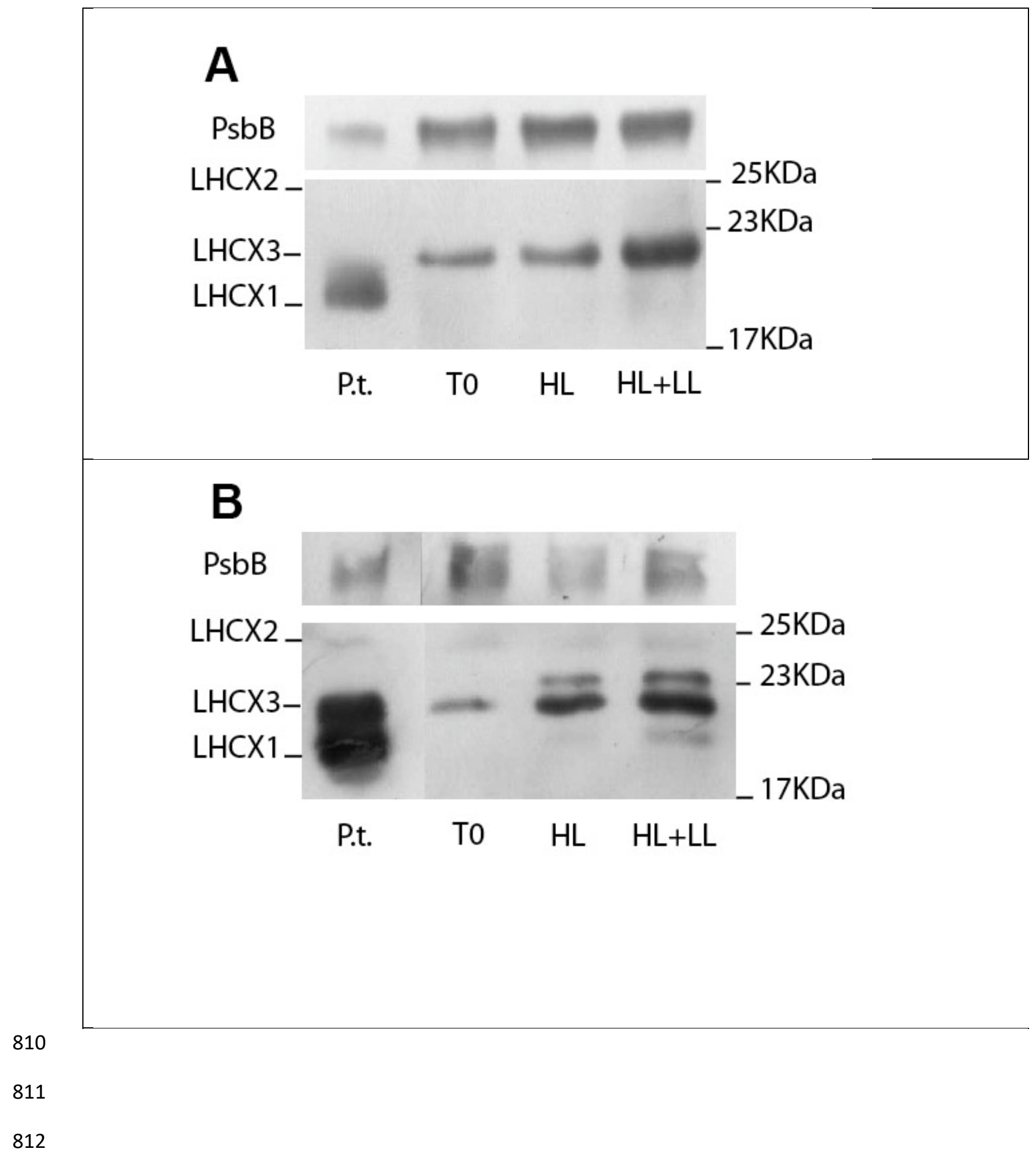




\section{Supporting material}

814 Fig. S1a,b\&c
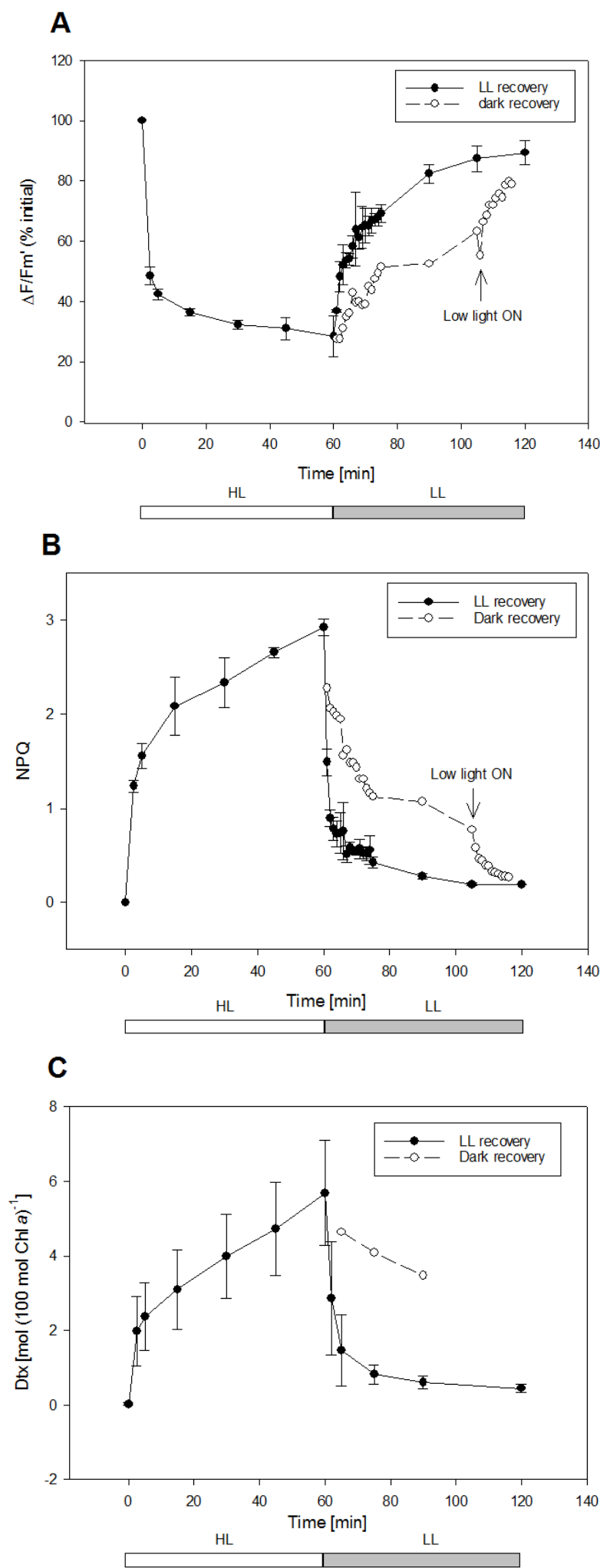
816 Fig. S1a,b\&c Dark recovery of O. guenter-grassii after HL exposure

817 O. guenter-grassii was exposed to one hour of HL $\left(2000 \mu \mathrm{M}\right.$ photons $\left.\mathrm{m}^{-2} \mathrm{~s}^{-1}\right)$ and one subsequent

818 hour of recovery in low light (LL, $20 \mu \mathrm{M}$ photons $\mathrm{m}^{-2} \mathrm{~s}^{-1}$ )(filled circles) or in dark recovery (open

819 circles) with LL onset at 105 min (indicated by an arrow). (a) Photosynthetic efficiency of PSII

$820 \Delta \mathrm{F} / \mathrm{Fm}^{\prime}$ is expressed in percentage of the maximal photosynthetic efficiency of PSII (Fv/Fm)

821 measured before high light onset. (b) Non-photochemical quenching (NPQ) and (c) Dtx,

822 expressed in mol $(100 \mathrm{~mol} \mathrm{Chl} a)^{-1}$. Values represent averages of three independent

823 measurements \pm standard deviations for the low light recovery treatment. For the dark recovery

824 treatment, only one replicate is plotted.

825 


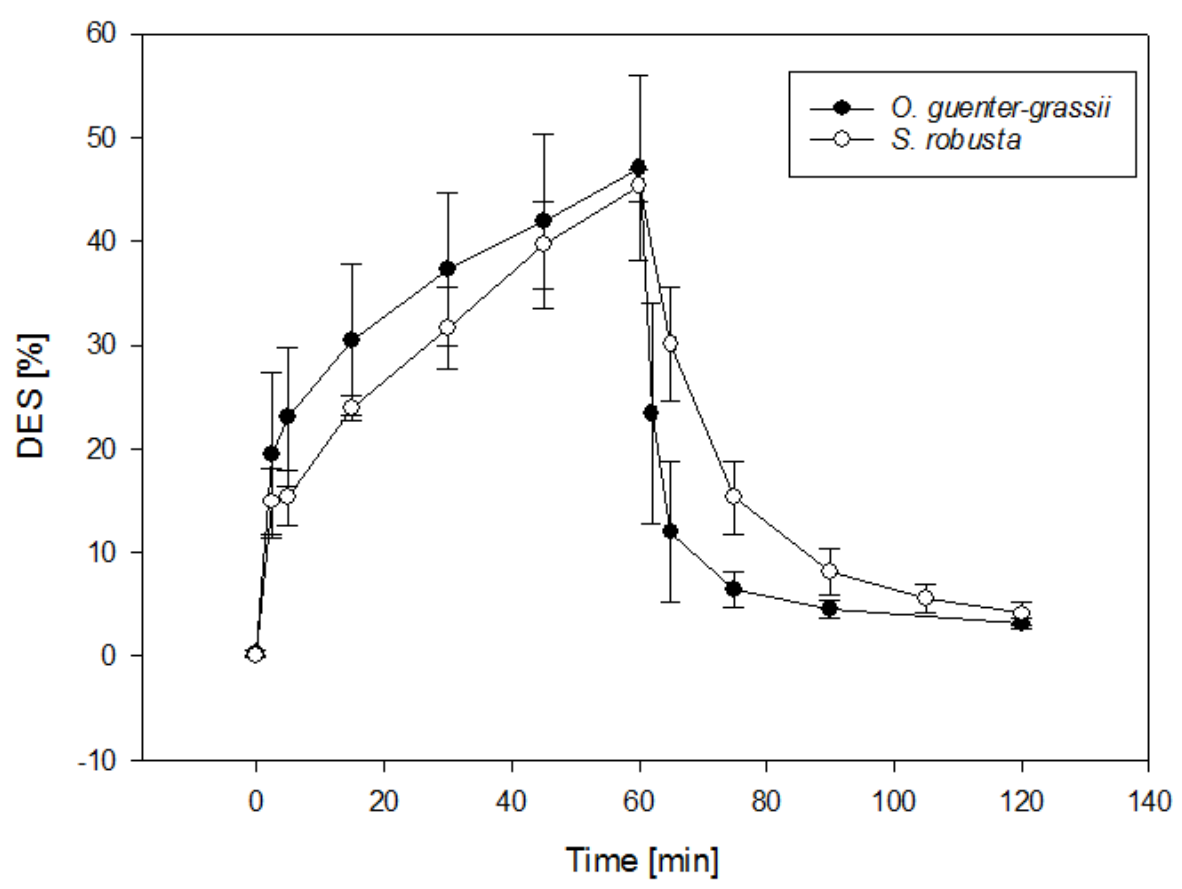

827

828 Fig. S2 De-epoxidation state of O. guenter-grassii and S. robusta

829 O. guenter-grassii (filled circles) and S. robusta (open circles) were exposed to one hour of HL

$830\left(2000 \mu \mathrm{M}\right.$ photons $\left.\mathrm{m}^{-2} \mathrm{~s}^{-1}\right)$ and one subsequent hour of recovery in low light (LL, $20 \mu \mathrm{M}$ photons

$\left.831 \mathrm{~m}^{-2} \mathrm{~s}^{-1}\right)$. De-epoxidation state (DES) was calculated as 100[Dtx/(Ddx+Dtx)]. 
Fig. S3a\&b

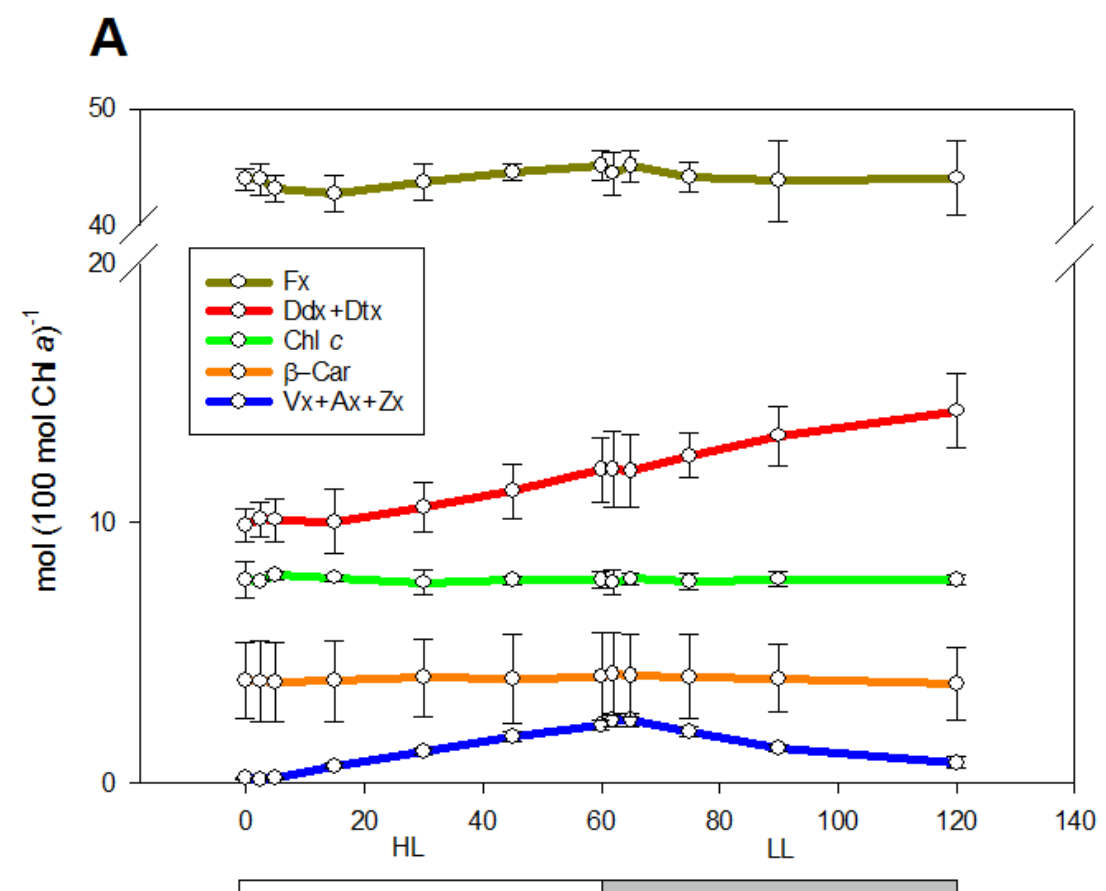

Time [min]

B

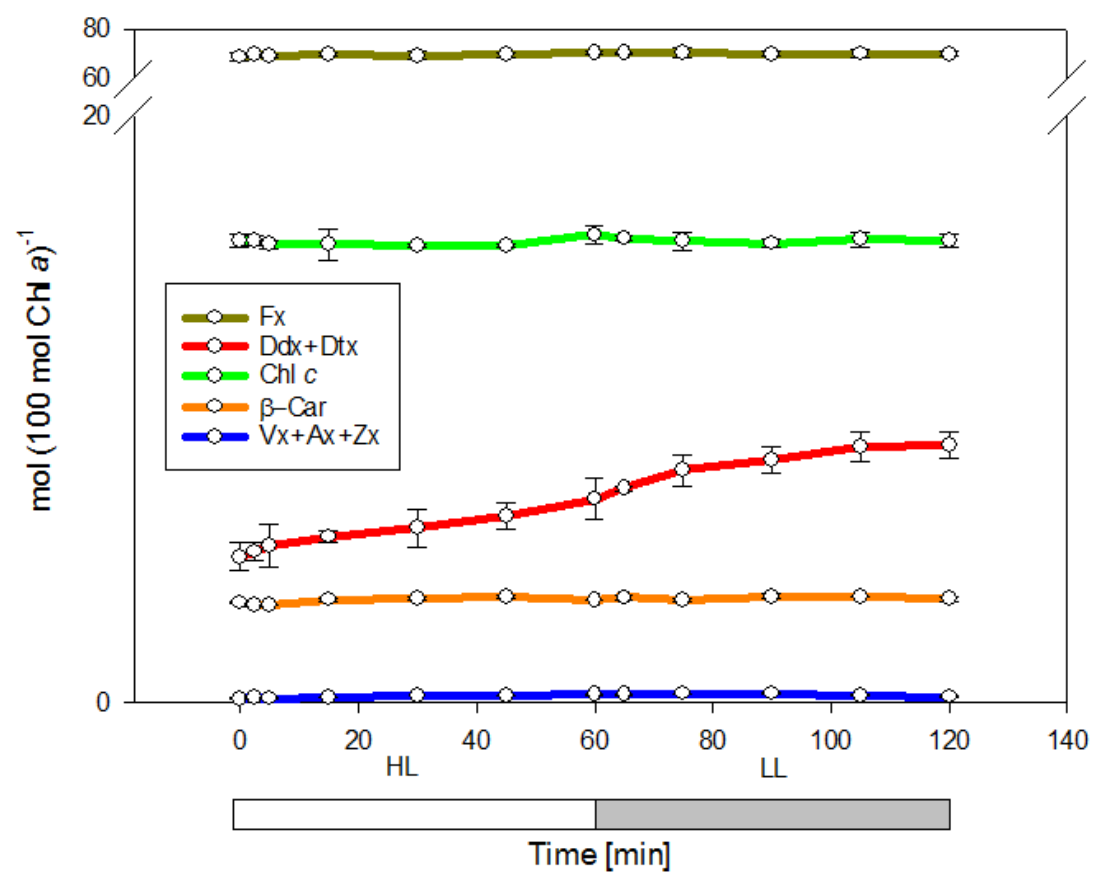

834 


\section{Fig. S3a\&b}

836 O. guenter-grassii and S. robusta were exposed to one hour of HL $\left(2000 \mu \mathrm{M}\right.$ photons $\left.\mathrm{m}^{-2} \mathrm{~s}^{-1}\right)$ and 837 one subsequent hour of recovery in low light (LL, $20 \mu \mathrm{M}$ photons $\mathrm{m}^{-2} \mathrm{~s}^{-1}$ ). (a) Pigment kinetics in 838 O. guenter-grassii; (b) Pigment kinetics in S. robusta. Abbreviations: Fx, fucoxanthin; Chl c, 839 Chlorophyll c; Ddx, diadinoxanthin; Dtx, diatoxanthin; Vx, violaxanthin; Ax, antheraxanthin; Zx, 840 zeaxanthin; $\beta$-car, $\beta$-carotene. 